\title{
EFFECTS OF MUSICAL VALENCE ON THE COGNITIVE PROCESSING OF LYRICS
}

\author{
Anna Fiveash \\ Master's Thesis
}

Music, Mind, and Technology

Department of Music

25 May 2014

University of Jyväskylä 


\begin{tabular}{|c|c|}
\hline $\begin{array}{l}\text { Tiedekunta - Faculty } \\
\text { Humanities }\end{array}$ & $\begin{array}{l}\text { Laitos - Department } \\
\text { Music Department }\end{array}$ \\
\hline \multicolumn{2}{|l|}{$\begin{array}{l}\text { Tekijä - Author } \\
\text { ANNA FIVEASH }\end{array}$} \\
\hline \multicolumn{2}{|c|}{$\begin{array}{l}\text { Työn nimi - Title } \\
\text { EFFECTS OF EMOTIONAL VALENCE ON THE COGNITIVE PROCESSING OF } \\
\text { LYRICS }\end{array}$} \\
\hline $\begin{array}{l}\text { Oppiaine - Subject } \\
\text { Music, Mind \& Technology }\end{array}$ & $\begin{array}{l}\text { Työn laji - Level } \\
\text { Master's Thesis }\end{array}$ \\
\hline $\begin{array}{l}\text { Aika - Month and year } \\
\text { MAY } 2014\end{array}$ & $\begin{array}{l}\text { Sivumäärä - Number of pages } \\
55 \text { or } 83 \text { with References and Appendices }\end{array}$ \\
\hline $\begin{array}{l}\text { Tiivistelmä - Abstract } \\
\text { The effects of music on the brain hav } \\
\text { connections have been found between music } \\
\text { and cognitive processing. Despite this work, } \\
\text { drawn together in a single research paradigm } \\
\text { lead to valuable insights into the effects of m } \\
\text { lyrics. Based on the feelings-as-information } \\
\text { analytic, systematic and fine-grained process } \\
\text { heuristic-based processing, the current study } \\
\text { found that significantly more error words we } \\
\text { music compared to positively valenced music }\end{array}$ & $\begin{array}{l}\text { d language, music and emotion, and music } \\
\text { he three research areas have never before been } \\
\text { ical valence on the cognitive processing of } \\
\text { ory, which states that negative moods lead to } \\
\text { detected when paired with negatively valenced } \\
\text { Non-musicians were better at detecting error } \\
\text { kers outperformed non-native English speakers. } \\
\text { d and happy lyrics have differential effects on } \\
\text { ad lyrics being processed at deeper semantic } \\
\text { ch to understand the interaction of lyrics and } \\
\text { nourage holistic and } \\
\text { ang to music. }\end{array}$ \\
\hline & \\
\hline
\end{tabular}


MUSIC, LYRICS, VALENCE, LANGUAGE, EMOTION, SEMANTICS

Säilytyspaikka - Depository

Muita tietoja - Additional information

\section{JYVÄSKYLÄN YLIOPISTO}




\title{
When you're happy, you enjoy the music. But when you're
} sad, you understand the lyrics.

\author{
- Frank Ocean
}




\section{Acknowledgements}

I would like to thank everyone involved with the MMT program - it has been a wonderful learning experience with lots of amazing memories along the way.

Thank you to my supervisor, Geoff Luck, for his continued support, feedback, and valuable input throughout the process, and for continuing to supervise me even when he didn't have to! Thank you to Marc Thompson, who has been continually supportive throughout the entire process, even baking chocolate chip banana bread to keep us motivated.

I am eternally grateful to my wonderful parents - Susanne Francisco and Mike Fiveash - for always being there in every way. For reading drafts, discussing ideas, keeping me sane, and posting Irish Breakfast tea on occasion :)

A big thank you to my friend and flat mate Elsa Campbell, who has helped make the past two years thoroughly enjoyable, and has offered continued moral support, baking adventures, Grey's Anatomy watching sessions, and general companionship. I couldn't have recorded all forty songs in one day without her!

To all my friends in Jyväskylä, especially Erica Eckhaus, Roseanna van Beek, Sarah Faber and Emily Carlson - thank you for the laughs, adventures, fun, and for making this one of the best experiences of my life! 


\section{Table of Contents}

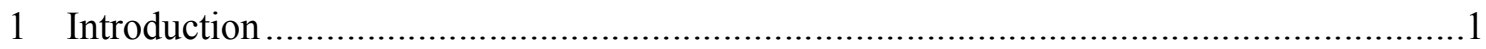

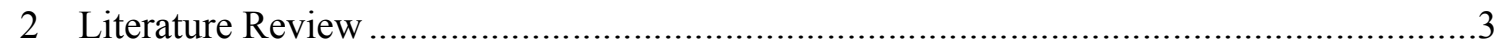

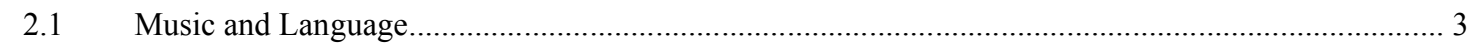

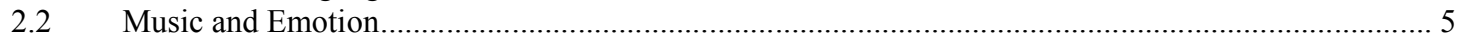

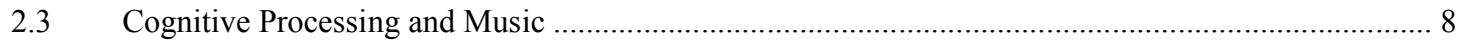

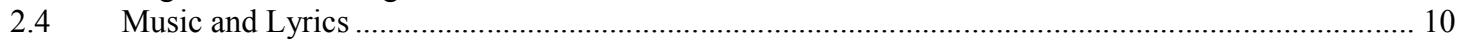

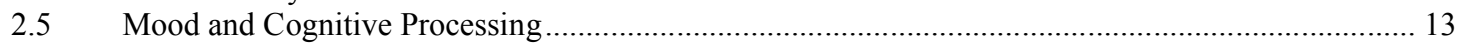

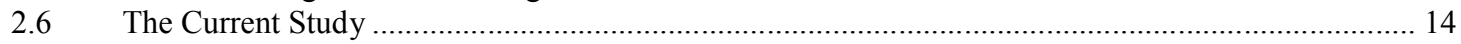

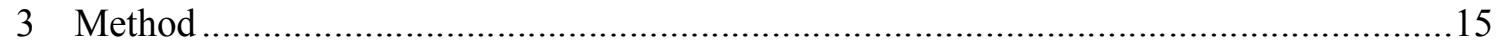

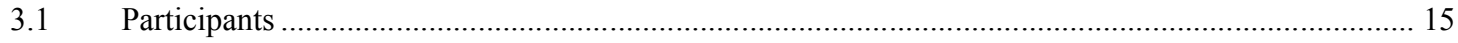

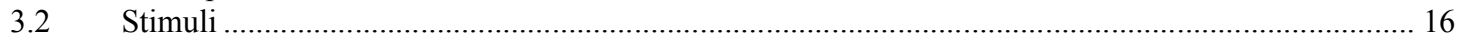

3.3 Semantic Errors ........................................................................................................................... 18

3.4 The Error Detection Paradigm as an Indicator of Cognitive Processing ............................................ 18

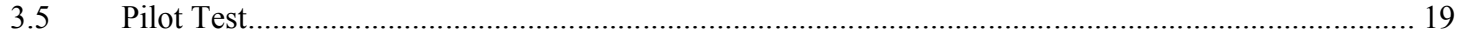

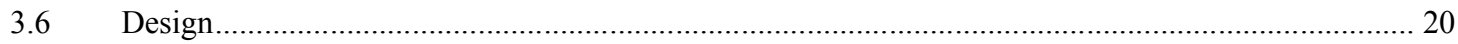

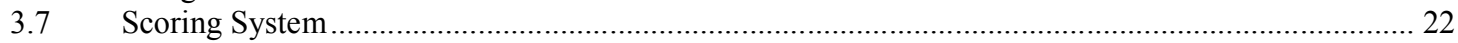

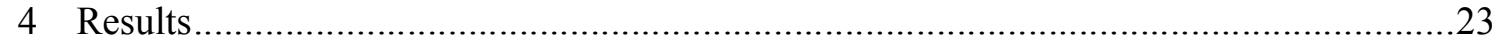

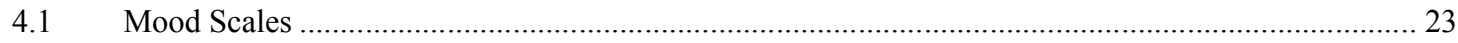

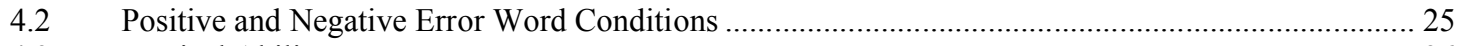

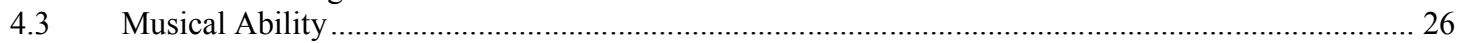

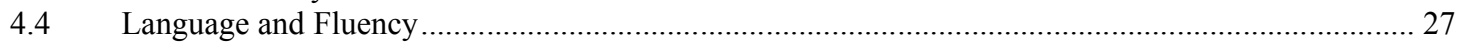

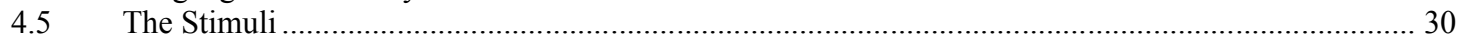

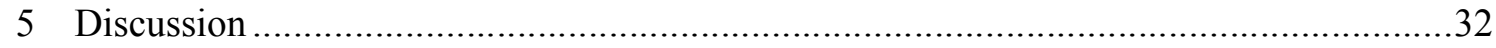

5.1 Feelings-As-Information Theory and Implications for Lyric Processing ................................... 32

5.2 Connections between Affect and Cognition ........................................................................ 35

5.3 Music Information Retrieval Combining Lyric and Audio Information........................................ 38

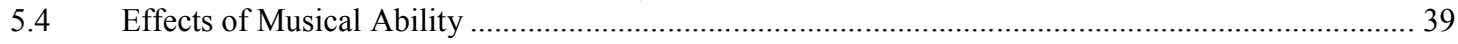

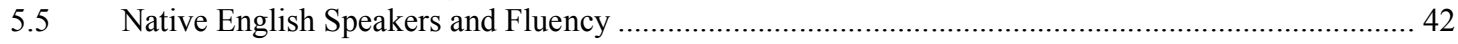

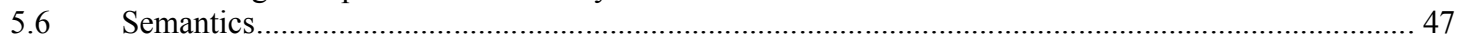

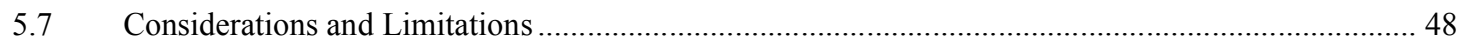

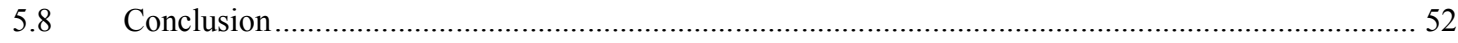

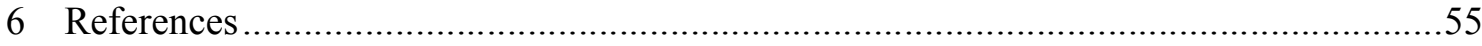

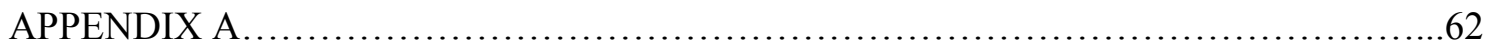

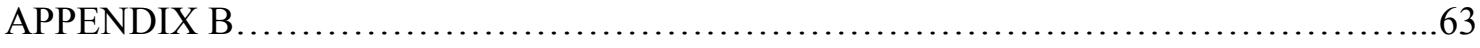

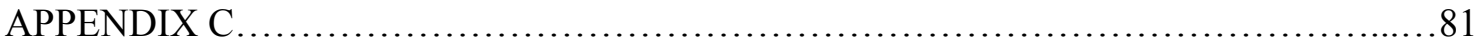

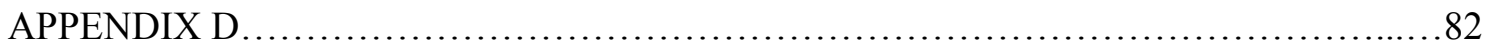




\section{List of Figures}

Figure 1: Examples of Negative and Positive Song Stimuli................................................17

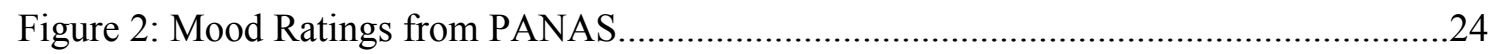

Figure 3: Positive and Negative Condition Scores for all Stimuli and all Participants............25

Figure 4: Scores for the Negative and Positive Conditions Depending on Musical Ability....27

Figure 5: Scores for the Negative and Positive Conditions Depending on English Speaking

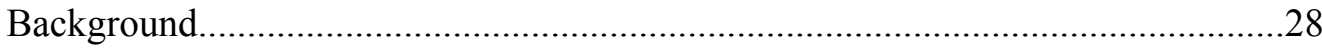

Figure 6: Scores for the Negative and Positive Conditions Depending on English Fluency....28

Figure 7: Scores for the Negative and Positive Conditions Depending on Self Report Ratings of Non-native English Speaker's Fluency.........................................................29

Figure 8: Scores for the Negative and Positive Conditions for Native English Speakers and Non-Native English Speakers who rated themselves as Fluent..............................30

Figure 9: Average Scores for Each Stimulus with an Error Word........................................31

\section{List of Tables}

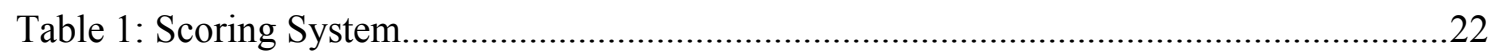




\section{INTRODUCTION}

Music, language, and emotion are three integral parts of the human experience that share many interesting connections and, when combined, can reveal much about human cognition. The fields of music and language research (e.g. Koelsch et al., 2002; Patel, 2008), and music emotion research (e.g. Juslin \& Sloboda, 2010) have so far progressed quite

separately. The combination of these two areas of research however, could allow for a greater insight into cognition.

The emotional effect of the combination of music and lyrics on the brain is not well understood. This is due largely to the majority of research on emotion induction and perception focusing on music without lyrics (see Juslin \& Sloboda, 2010). While such research is valuable in mapping the emotional response of listeners to music, it is not complete. As a large amount of popular music contains both music and lyrics, it is important to understand the effect of the combination of music and lyrics in inducing emotion in the listener.

Initial research into how the brain processes music with lyrics in relation to emotion suggests that the valence of the music (positive or negative) has an effect on the way lyrics and music interact. A behavioural study by Ali and Peynircioğlu (2006) found that the addition of sad lyrics enhanced the perception of sadness for listeners, while the addition of happy lyrics detracted from the perception of happiness for listeners, suggesting an effect of lyrics that differs depending on the emotional content of the music. While they found this a surprising result, possible explanations for this occurrence were not discussed.

A more comprehensive study by Brattico et al. (2011) investigated the combination of lyrics and music on emotion induction using functional magnetic resonance imaging (fMRI). This was the first music and emotion fMRI study that examined music with lyrics (Brattico et 
al., 2011). Overall, the authors found an effect of lyrics that was dependent on the emotional content of the music. Much larger activations in the brain in response to sad music with lyrics, and to happy music without lyrics were found, compared to sad music without lyrics and happy music with lyrics. More specifically, there was significantly more activation in the limbic system (the emotion centre of the brain) in response to sad music with lyrics, and to happy music without lyrics. This led the authors to the conclusion that these combinations of music and lyrics are experienced at a deeper level in the brain than their counterparts. Interestingly, sad music with lyrics activated Brodmann Area 47 (an area that specialises in both music and language syntax) to a greater extent than happy music with lyrics, suggesting that the lyrics were being processed to a greater extent when paired with sad music.

The finding that sad lyrics paired with sad music increases the sadness of the music, while happy lyrics paired with happy music decreases the happiness of the music, warrants further investigation. Ali and Peynircioğlu (2006) did not put forward a theory as to why such an effect occurred, and Brattico et al. (2011) discussed some speculative explanations, but concluded with the idea that, for emotion induction, acoustic cues are more important in happy music, while lyrics are more important in sad music. Although this appears to be the case based on their findings, the underlying mechanisms behind such an occurrence remain unknown. The current thesis will combine music and language research, music and emotion research, and research into cognitive processing, to propose that such an effect occurs due to musical valence (positive or negative), affecting the cognitive processing of lyrical information, which in turn leads to differing effects of lyrics on emotion induction in listeners. 


\section{LITERATURE REVIEW}

The following section considers separately research on music and language, music and emotion, and cognitive processing. These are then drawn together to support the hypothesis that musical valence affects lyrical processing.

\subsection{Music and Language}

Much work has been carried out on the connections between music and language by evolutionary psychologists (e.g. Mithen, 2009); neuroscientists (e.g. Koelsch et al., 2002); and psychologists (e.g. Patel, 2008). Music and language have been shown to draw on similar processing mechanisms, and show similarities in terms of perception (Bidelman, Gandour, \& Krishnan, 2011), semantics (the meaning inherent in the language/music; Koelsch et al., 2004), syntax (the rules of the structure, e.g. grammar/note-hierarchies; Maess, Koelsch, Gunter, \& Friederici, 2001) and transfer effects (Besson, Chobert, \& Marie, 2011). The similarities in structures, hierarchies and rules governing the creation of both language and music have also been compared (Johansson, 2008). Strong evolutionary links between the two domains have been shown, with music often considered as a precursor to language and communication (Mithen, 2009). Furthermore, both music and language are considered as universal human traits across cultures (Peretz, 2006). Findings that lyrics and music can mutually affect each other therefore come as no surprise.

Research has shown that many areas previously thought to be responsible primarily for language processing - including Broca's area, Wernicke's area, and Heschl's gyrus - are also used in the processing of music (Koelsch et al., 2002). An fMRI study by Patel, Gibson, Ratner, Besson, and Holcomb (1998) found that a positivity was elicited in the brain (the P600) in response to a syntactic anomaly in both music (out of key chord) and in language 
(grammatical error) that was indistinguishable, suggesting that syntactic errors are processed in the same area. While much work has investigated similarities in syntactic processing between music and language (for instance Fiveash \& Pammer, 2014; Maess et al., 2001; Patel, 2007), less is known about semantic processing similarities between music and language, as semantics in music are difficult to define. Koelsch and colleagues (Koelsch et al., 2004; Koelsch, 2011) have, however, found that both music and language can prime semantic meaning, and that semantic processing can elicit similar brain responses to both music and language stimuli. This interaction between semantic processing in music and language suggests that the combination of lyrics and music may affect each other depending on the semantic content of each.

There is currently a debate in the field of music and language research about whether music and language are processed separately or together in the brain (e.g. Peretz \& Coltheart, 2003; Patel, 2008). This approach, however, seems somewhat simplistic, and research would benefit from a focus on mapping the networks activated by both domains, rather than arguing whether they are similar or not. Alluri and colleagues (Alluri et al., 2012) show the extensive networks of the brain activated when naturalistic music is listened to; and a large number of studies show complex connections between music and language processing (e.g. Patel, 2008). For example, Sammler et al. (2010) found that at a phoneme processing level, music and lyrics were processed together, while at another level (speculated to be where semantic meaning is attributed to the lyrics), the lyrics were processed independently. They further found that music and lyrics were again united when the overall representation of the music and lyrics were linked together. While some researchers do argue for a separation of processing (Besson, Faita, Peretz, Bonnel, \& Requin, 1998; Peretz \& Coltheart, 2003), the general consensus among music and language researchers is toward an integrated, complex model of music and language processing (e.g. Koelsch et al., 2002; Maess et al., 2001; Patel, 
2008). Such research suggests a complex interplay of music and language that cannot be explained in a simple way.

\subsection{Music and Emotion}

Music and emotion research is a complex field, as understanding emotions induced and perceived through music involves a range of issues, including untangling connections between the music, the listener, and the situation, the measurement of emotion, and deciphering the subjective nature of human emotions (Juslin, Liljeström, Västfjäll, Barradas, \& Silva, 2008; Juslin \& Sloboda, 2010). While the general consensus is that music can induce strong emotions (Juslin \& Sloboda, 2010; Lundqvist, Carlsson, Hilmersson, \& Juslin, 2009), and that a primary reason people listen to music is to induce emotions (Juslin \& Laukka, 2004), the types of emotions able to be induced, differences between induction and perception of emotion in laboratory settings, and even the definition of 'emotion' itself, is still under debate (Juslin \& Västfjäll, 2008). The subjective and personal nature of emotions, as well as their context dependence, makes research into emotions difficult, and often yields controversial results (Juslin \& Västfjäll, 2008). While this is so, research into the effects of musically induced emotions has yielded some compelling results (see Juslin \& Sloboda, 2010).

A common debate in the field of music and emotion research is how to measure musically induced emotions. As musically induced emotions are not as well understood as those in everyday life (see a discussion by Juslin \& Västfjäll, 2008), a common practice in music emotion research has been to base the measurement of musically induced emotion on models of everyday emotions. For example, much work on musically induced emotion has measured emotion using discrete, basic emotion categories, looking primarily at happiness, 
sadness, anger, fear, disgust and surprise (Baumgartner, Esslen, \& Jänke, 2006). This is based on Ekman's (1992) basic emotions model, in which it is argued that these are the basic evolutionary emotions which can be clearly distinguished among facial expressions crossculturally, and are linked to survival. While this theory is quite widely accepted, definitions of basic emotions are still being modified and expanded (Ekman, 1999; Levenson, 2011). While such emotion models seem to represent everyday emotions, some music researchers have argued that music induces different varieties of emotions that cannot be explained through basic emotion models, and that a theory of music induced emotions is necessary (Juslin \& Västfjäll, 2008; Zentner, Grandjean, \& Scherer, 2008).

The subjective nature of emotions, and musical emotions in particular, makes it difficult to arrive at a consensus on how to measure emotions induced by music. Leading researchers in the field, Juslin and Västfjäll (2008) suggest that the field of music and emotion is suffering from a lack of understanding of the basic underlying mechanisms related to emotion induction, and indeed, the distinction between induction and perception of emotion. They suggest that researchers need to identify the underlying mechanisms they are focusing on, as this will influence their experiment design and measurement tools. Scherer (2004) argues that the three main ways music researchers are measuring emotions - via basic emotion lists, valence-arousal spectrums, and other independent measurement tools - do not appropriately account for music induced emotion. He suggests that a musical emotions scale be created that is corroborated and specifically linked to emotions induced by music.

Following from Scherer (2004), Zentner et al. (2008) created a theory of musicinduced emotions called the Geneva Emotional Music Scale (GEMS), consisting of nine emotions specifically related to music. These nine emotions (wonder, transcendence, tenderness, nostalgia, peacefulness, power, joyful activation, tension, and sadness) were based on a factor analysis of 515 terms which were compiled from many sources. Through testing 
and elimination, this list was condensed to 146 terms. The words were then presented to 262 students, who were grouped by preference for five different musical genres, and asked how often they both felt and perceived the 146 different adjectives while listening to music. This was then condensed by factor analysis into the nine-emotion model. A major difference between normal emotion models and the GEMS model was that music induced emotions seem to instil less negative emotions than those in discrete emotion models (for example disgust, fear etc.). Zentner et al. (2008) suggested this was because negative emotions were less relevant to music listening, as listeners are unlikely to relate the emotion from the music as threatening. They did however ask participants to focus on music without lyrics when making these ratings, which could have implications for the validity of the GEMS when generalising to musically induced emotions in music with lyrics.

There is a debate about whether musical emotions should be measured via discrete (categorical) means, or on a continuous (dimensional) scale (Eerola \& Vuoskoski, 2011). GEMS is a discrete model that filters musically induced emotion into one of nine categories. While these have been shown to be linked to music listening, by limiting the choice to nine emotions a lot of understanding about musically-induced emotions may be lost. Eerola and Vuoskoski (2011) on the other hand have proposed a two-dimensional model of valence and arousal that can help map musically-induced emotions along these two dimensions. They suggest this is a better way of understanding both musical emotions, and emotions induced by musically ambiguous situations. While these models are based on different underlying theory (discrete versus continuous), they are both useful in understanding musically induced emotions. There is still much work to be done to understand more clearly the mechanisms involved in musical emotions, however these models are a good start in measuring these emotions while maintaining a level of consistency across studies. 


\subsection{Cognitive Processing and Music}

Musically induced emotions, and transient mood states, have also been shown to affect cognitive processing, and language processing in particular. A study by Olafson and Ferraro (2001) induced mood by playing eight minutes of classical music that was either happy or sad, and then presented participants with happy words, sad words, and pseudo words. They found that happy words were processed more quickly in the happy group, and sad words processed more quickly in the sad group. This effect has been shown in a number of studies, and is thought to be due to mood congruent recall. For example, Tesoriero and Rickard (2012) exposed participants to positive or negative music, and then presented them with positive or negative narratives. Those in the positive music group could recall more from the positive narratives than the negative narratives, and the same pattern was found for those in the negative music group. This mood congruence theory is quite robust, and has been found in other domains as well (Drace, 2012; Edigi \& Gerrig, 2009; Edigi \& Nusbaum, 2012). Such research is important to the understanding that music can induce emotions which alter the way we process information.

In addition to mood congruence effects, research has also shown that priming a mood can affect the way subsequent information is processed in the brain. Vuoskoski and Eerola (2012) induced sadness in participants through both music and by making participants recount autobiographical memories, and found that both memory and judgement for emotion related stimuli were affected. Jiménez-Ortega et al. (2012) found that the processing of neutral sentences (measured by error detection and reaction time to semantic and syntactic errors) differed significantly depending on whether a priming paragraph was positive or negative. They found that when the priming paragraph was positive, error detection was lower, and reaction time higher for semantic and syntactic errors, compared to when the priming 
paragraph was negative. Such a result suggests that positive priming leads to poorer performance in sentence processing, while negative priming leads to better performance (Jiménez-Ortega et al., 2012). This suggests that transient mood states, or priming, can affect the way language is processed.

Research by Vissers et al. (2010) looked at the effect of mood on language processing, and found an interaction between mood and the P600 brain response elicited with syntactic anomalies in language. It was found that positive mood led to a greater P600 effect, whereas negative mood led to a lesser P600 effect, showing a greater effect of the syntactic anomaly on people in a positive mood. The authors suggest this may be to do with heuristics, in that people in a negative mood pay more attention to detail to begin with, and therefore notice the anomaly straight away, whereas people in a positive mood are more likely to use heuristics while parsing the sentence, and therefore show a greater expectation violation (reflected in the higher P600) and have to reprocess the sentence. Emotion clearly has an effect on the way our brain processes language, and therefore it could be speculated that the valence of music would affect the way we process the lyrics that it is paired with.

An EEG study conducted by Federmeier, Kirson, Moreno, and Kutas (2001) showed that mood can influence language processing in terms of semantic memory retrieval. Federmeier et al. (2001) used pictures to induce positive or neutral mood, and then presented participants with 132 sentences that ended with: a) the most expected ending; b) an unexpected ending, but with a word in the same semantic category; or c) an unexpected ending from a different semantic category. The participants' brain responses to these sentences were then recorded both when they were in a neutral mood and when they were in a positive mood. As this was a within subjects design, the authors were able to show that with the same participants and the same stimuli, different brain activations occurred depending on whether they were in a neutral or positive mood, clearly showing that mood influences the 
way our brain responds to semantic stimuli. They concluded that transient mood states affect online semantic processing.

\subsection{Music and Lyrics}

With numerous studies showing how transient mood states can affect the way the brain processes linguistic information, it is plausible to assume that the musical valence of a piece of music can affect the way lyrics are processed. Research looking at music with lyrics has generally been confined to investigating how music and lyrics are processed in the brain (e.g. Gordon, Schön, Magne, Artésano, \& Besson, 2010; Peretz, Radeau, \& Arguin, 2004), rather than how they interact to induce mood. As much popular music contains lyrics (see Brattico et al., 2011), and it is commonly stated that one of the main reasons people listen to music is because of its ability to evoke emotions (Juslin \& Laukka, 2004), it is important to understand the effects of music with lyrics on emotion induction. This is also important for music therapy settings and in music information retrieval (MIR) work.

The role of lyrics in inducing emotion through music is being uncovered in various areas of study, both in psychological research, and music information retrieval studies. MIR concerns the extraction of features of music to allow for classification, recognition and analysis of music via computer programs (Downie, 2003). Research into the effects of lyrics on music mood classification gained importance as MIR specialists discovered the role of lyrics in classifying the mood of a piece of music. For example, Mihalcea and Strapparava (2012) show that lyrics add a significant amount of semantic meaning to a song, and that the use of both music and lyrics lead to a greater accuracy in classifying a song into a particular mood category. Hu and Downie (2010b) found that, for some songs, and in some emotion categories, lyrics are actually more important than music in classifying the emotional content, 
and that this differs depending on the emotion being conveyed. Studying the effects of lyrics on mood induction is therefore both necessary and informative. If it is seen that lyrics are processed differently depending on the valence of the music they are paired with, it is possible to create algorithms for MIR which give more weight to either the lyrics or the music, so as to reflect human processing.

The combined effect of lyrics and music on cognitive processing has received little attention. The combination of lyrical and musical information in an ecologically valid medium such as song, however, is a useful way of understanding connections between music and language in the brain. One study investigating how music and lyrics are processed in the brain asked participants to focus on either the melody or the lyrics while performing a samedifferent task (Gordon et al., 2010). When focusing on the lyrics, unexpected lyrics elicited an N400 (a negativity associated with semantic processing) in the brain. The same N400 was elicited when the lyrics were the same but the music was unexpected. This suggests that music can alter the way lyrics are processed, even when attention is directed towards lyrics. Such a finding adds further support to the notion of shared processing networks between music and language, and suggests that there is an interaction in processing between music and lyrics. While Gordon et al.'s (2010) study claimed to have used ecologically valid stimuli in the form of 'songs', the stimuli presented contained only three notes and a three-syllable word. While this is indeed the basic form of a song, one word and three notes do not convey the appropriate semantic meaning inherent in songs, either through lyrical or musical information. Further research on the relationship between lyrics and music in ecologically valid songs is thus warranted.

Research into the combination of music and lyrics has suggested differential effects of lyrics on emotion induction depending on the emotion of the music (Ali \& Peynircioğlu, 2006; Brattico et al., 2011). Ali and Peynircioğlu (2006) found that the addition of sad lyrics 
enhanced the perception of sadness for listeners, whereas the addition of happy lyrics detracted from the perception of happiness for listeners, suggesting an effect of lyrics that differs depending on the emotional content of the music. They also found that melody was more dominant than lyrics in the perception of emotion, but that emotions were rated as more intense when the music and the lyrics were congruent, suggesting that music and lyrics both play an important role in emotion perception. While differential effects of lyrics were found depending on the emotional content of the music, possible explanations for this were not discussed. Such a result, however, deserves further research to investigate why such an effect is occurring; how the emotion in the music might modulate the effect of lyrics on emotion perception; and to see whether a similar effect is apparent in induced emotion.

Research has shown that the effect of lyrics on emotion induction in a listener is dependent on the emotional content of the music. Brattico et al. (2011) conducted an fMRI study which found that sad music with lyrics and happy music without lyrics activated the brain to a greater extent than their counterparts. The greater activation in the limbic system to sad music with lyrics, and to happy music without lyrics, points toward different processing mechanisms involved when the lyrics are paired with happy or sad music, as there are clear differences in the way lyrics are processed in the brain depending on the type of music they are paired with. The fact that Brattico et al. (2011) found that an important language area in the brain (Brodmann's Area 47) was activated more when listening to sad music with lyrics than happy music with lyrics further suggests that lyrics are processed differently in the brain depending on the valence of the music.

The results from Brattico et al. (2011) and Ali and Peynircioğlu (2006) are suggestive of a difference in lyric processing depending on the valence of the music they are paired with. Brattico et al. (2011) propose that this reflects the hypothesis that lyrics are more important for emotion induction in sad music, and that musical cues are more important for emotion 
induction in happy music. They further speculate that the greater emotional effect of sad lyrics could be related to the tone in the singer's voice activating deep emotional pathways in the brain; or that sad lyrics could elicit negative memories or representations in the mind, leading to greater activation of emotion areas in the brain. Another explanation not mentioned by Brattico et al. (2011), but supported by cognitive theories of language processing, is that the difference in emotion induction depending on the valence of the music is due to transient mood states altering the way the lyrics are processed.

\subsection{Mood and Cognitive Processing}

The effects of positive and negative mood on the processing of stimuli have been well documented (Mitchell \& Phillips, 2007), and a leading theory concerning effects of mood on cognitive processing is the feelings-as-information theory (Schwarz, 2010). The feelings-as information theory is an influential theory in social psychology, and is based on the evolutionary principle that negative moods reflect danger in the environment, whereas positive moods reflect safety. This is supported by a number of studies (e.g. Beukeboom \& Semin, 2006; Gasper \& Clore, 2002; Vissers et al., 2010) that have found that negative moods lead to systematic, analytic, detail oriented and local level processing, while positive moods lead to heuristic processing (using mental shortcuts), less focused attention, higher creativity and global level processing. Feelings-as-information therefore refers to the idea that feelings inform us about the environment, and therefore feelings (or mood) influence the appropriate processing strategy to deal with the situation.

The feelings-as-information theory is a good explanation of why lyrics appear to play a different role in emotion induction depending on the valence of the music. It could be hypothesised that when the music is positive, listeners process the lyrics with less focused 
attention, and use heuristic techniques. This would lead them to not completely focus on the semantic content of the lyrics. When the music is negative, however, this would be hypothesised to activate more focused, analytic and detailed processing. This would lead to the lyrics being processed at a deeper level when paired with sad music. This has indeed been shown in the Brattico et al. (2011) study, where it was found that sad music with lyrics activated deeper semantic structures compared to happy music with lyrics. It would also explain why Brattico et al. (2011) found greater activation in the limbic system for sad music with lyrics, compared to happy music with lyrics.

\subsection{The Current Study}

The overarching hypothesis of the current study is that musical valence (positive or negative) will affect the processing of lyrics. To measure cognitive processing of lyrics, an error detection paradigm was employed. Forty songs were composed, half of which had semantic errors within the lyrics. After listening to each song, participants had to indicate whether there was an error in the lyrics. The error detection paradigm is similar to that used by Jiménez-Ortega et al. (2012), who primed participants with paragraphs of different valences, and then presented them with sentences with a semantic violation, a syntactic violation, or no violation. In this experiment, the 'priming' will effectively be the positive/negative valence of each song. Semantic violations (instead of syntactic) were chosen because of the emotional nature of the stimuli. Semantics refers to the meaning inherent in structures - such as music and language. As the stimuli will be music of a positive or negative valence paired with lyrics of the same positive or negative valence, semantic violations seem the most suited to test cognitive processing in this paradigm. 
The current study hypothesises that error detection will be lower for semantic errors in lyrics paired with positive music, and that error detection will be higher for semantic errors in lyrics paired with negative music. Such a hypothesis draws from studies showing that music and language share similar processing resources and can influence each other (e.g. Patel, 2008); that mood influences language processing (Vissers et al., 2010), and that music can induce strong emotions or moods in listeners (Juslin \& Sloboda, 2010). These three areas of research have not been combined previously in studying the way music and lyrics interact. This study will therefore investigate how music induced mood affects the way that lyrics are processed, and how this in turn affects the interaction of music and lyrics depending on the valence of the music.

\section{METHOD}

To test the hypothesis that positive music will lead to lower levels of error detection in lyrics, and negative music will lead to higher levels of error detection in lyrics, an online questionnaire was designed using Qualtrics (Qualtrics, Provo, UT, http://www.qualtrics.com), and distributed through social media. An online questionnaire was chosen to allow for a large number and a wide variety of participants. Participants were in a music listening location of their own choice, making the music listening situation more ecologically valid than in a laboratory, and satisfying to a certain extent the three important aspects of music emotions the listener, the music, and the situation (Juslin \& Laukka, 2004).

\subsection{Participants}

Sixty-four participants (41 women, 23 men, $M_{\text {age }}=30.06$ years, age range: $18-72$ ) completed the online questionnaire. Of these participants, 64\% were native English speakers, 
$30 \%$ were non-native English speakers, and 6\% were raised bilingual, with $89 \%$ rating themselves as fluent in English, and 11\% rating themselves as mostly fluent (to the question: Are you fluent in English? Possible answers: Yes; Mostly; Somewhat; No). Participants rated themselves on level of musicianship, with $12.5 \%$ identifying as 'Non-musician'; $33 \%$ identifying as 'Music-loving Non-musician’; $37.5 \%$ as 'Amateur Musician’; $14 \%$ as ‘Semiprofessional Musician'; and 3\% as 'Professional Musician'. Participants were asked to wear headphones for the duration of the experiment, and $84 \%$ of participants reported wearing headphones, while $16 \%$ did not.

\subsection{Stimuli}

The questionnaire presented participants with 40 one-minute original songs consisting of both music and lyrics. Of these, 20 were written as positive songs, and 20 as negative songs, with mood congruent lyrics. Each song had an intro of approximately 15 seconds before the lyrics began. The music was composed according to guidelines on what constitutes positive and negative music - most importantly tempo and mode (Juslin \& Laukka, 2004). Negative songs were in minor keys and averaged 80 beats per minute (bpm), while positive songs were in major keys and averaged $140 \mathrm{bpm}$. Both the positive and negative songs had an average of 55 words per song, which kept the amount of lyrics to be processed relatively consistent for each song. The songs were spread evenly in relation to key, with all main musical keys represented (see Appendix A). The lyrics followed positive or negative themes, drawn from social media sites such as Tumblr, upon keyword searches of happiness and sadness and similar related words. The songs were recorded in a professional studio, sung by the composer to enhance emotional expression, and played on an acoustic Landola, nylon string guitar. Vocals were recorded with an Audio Technica 4033 microphone, and guitar 
recorded on a Royer R122 Ribbon microphone. Minimal effects were added to the recordings. Examples of positive and negative song lyrics and chords are shown in Figure 1, and all the songs are shown in Appendix B.

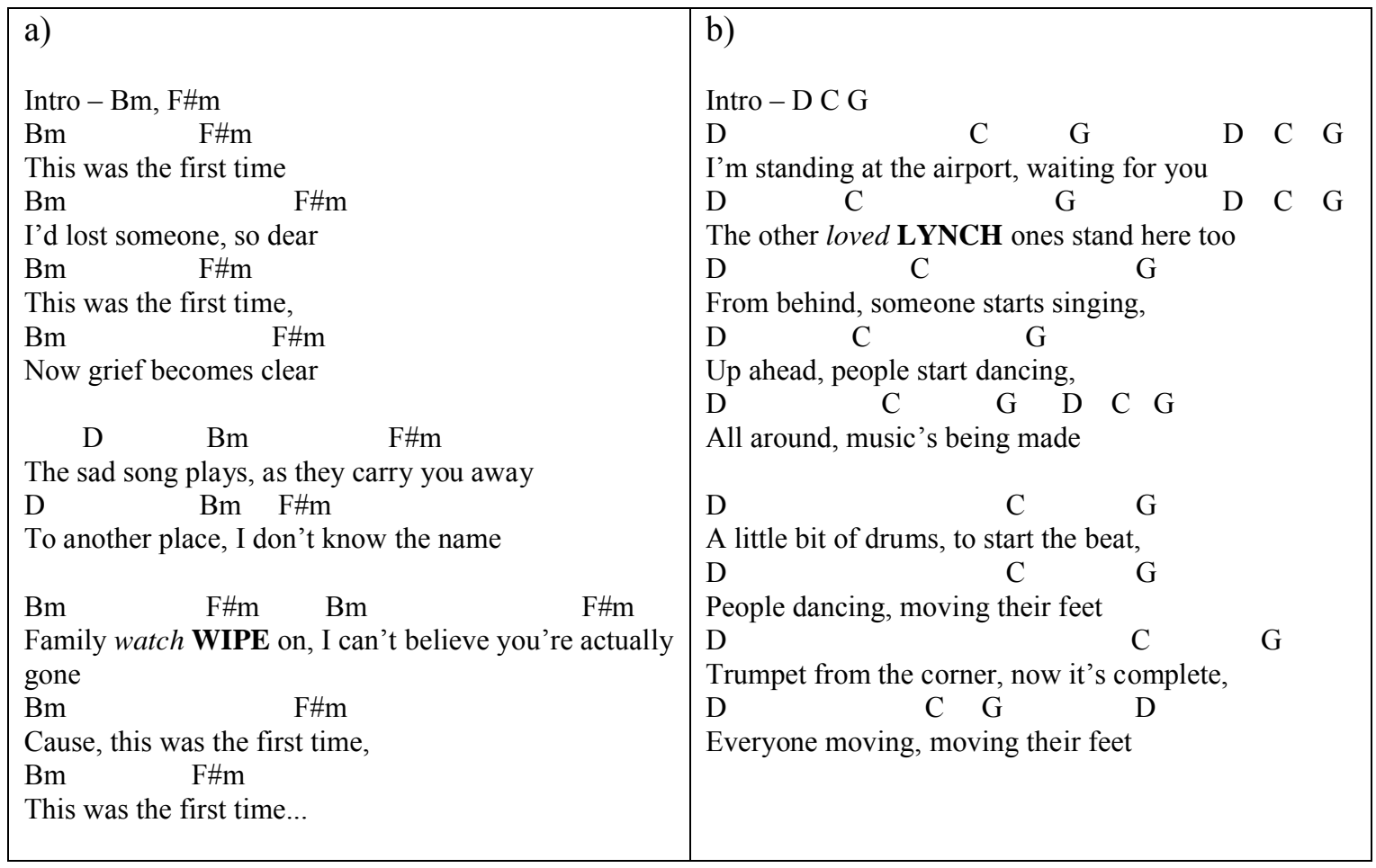

Figure 1: Examples of negative and positive song stimuli. Error words are in capital letters and replaced the italicised words; (a) is a negative song with 56 words and played at $84 \mathrm{bpm}$; (b) is a positive song with 56 words and played at $144 \mathrm{bpm}$.

While literature does suggest increased emotional response to familiar songs (Brattico et al., 2011; Pereira et al., 2011), original songs were chosen as they would not interact with pre-learned expectations of the lyrics, or introduce variability in episodic memories linked to familiar songs. In addition, the music was written and recorded for the same instrument, by the same composer, and sung by the same voice, which minimises variability across stimuli. 


\subsection{Semantic Errors}

Half of the songs were randomly chosen to contain a semantic error in the lyrics.

Songs were randomised within the positive and negative conditions, resulting in ten positive and ten negative songs being selected to contain a semantic error. A random word was then selected to be changed semantically. If the word was not suitable for changing or the word was one that was sung too quickly, then the closest suitable word was chosen to be changed. Words that were not suitable for changing were connecting words such as 'the', 'a', 'I' etc., because they were not content words and did not hold any semantic meaning. Semantic error words were chosen from the Medical Research Council (MRC) Psycholinguistic Database (Coltheart, 1981; http://websites.psychology.uwa.edu.au/school/MRCDatabase/uwa mrc.htm). Words were generated that started with the same letter, and had the same number of syllables as the word that was to be replaced. From this list, a word that fit musically but did not make semantic sense within the sentence was chosen.

\subsection{The Error Detection Paradigm as an Indicator of Cognitive Processing}

The error detection paradigm was used because it was considered a good way to behaviourally assess cognitive processing, compared with other factors such as memory. For an error word to be detected, the participant had to both be paying attention to the lyrics, as well as integrating the semantic information in the sentences. If semantic integration was lacking or attention was not focused, this would reflect lower levels of cognitive processing. Such a paradigm has been used in previous studies to assess cognitive processing, attention, and brain responses to both semantic and syntactic violations in language (Jiménez-Ortega et al., 2012; Rüschemeyer, Fiebach, Kempe, \& Friederici, 2005), as well as in music (Koelsch, 
Jentschke, Sammler, \& Mietchen, 2007; Patel et al., 1998). The widespread use of the error detection paradigm especially for syntactic and semantic errors shows that these errors elicit particular responses in the brain to both syntactic and semantic violations (Hagoort, 2003), are a good indication of cognitive processing and increased cognitive load, and are therefore suitable for the aims of the current experiment.

\subsection{Pilot Test}

The 40 songs were pilot tested to ensure they induced the intended emotion, and to test the effects of the error words. There were six pilot test participants, four females and two males. Four had musical training, and one was a fluent non-native English speaker. Participants were given full instructions prior to commencing the experiment (see Appendix C). Each participant listened to all 40 songs, in blocks of 20 positive and 20 negative songs. Presentation order of the positive and negative blocks was alternated between participants. The presentation of the songs within these blocks was also randomised for each participant.

The participants were instructed to listen to each song (the files were accessed via a Dropbox link), and then asked: was there an error in the lyrics? (yes/no); if so, what was the error word? and to rate how positive/negative the song was (depending on the block) on a 5point Likert scale, where $1=$ not at all; $2=$ not very; $3=$ somewhat; $4=$ quite; $5=$ very. The positive and negative affect schedule (PANAS; Watson, Clark, \& Tellegen, 1988) was administered before any stimuli presentation for a baseline measure, after positive, and after negative blocks. The participants were also asked to give general comments and did not complete the experiment proper.

The results showed that most of the songs were rated as highly representative of the intended emotion (positive songs mean positive rating $=4.01$; negative songs mean negative 
rating $=3.9$ ). Four negative songs received ratings below 3.5, and these were subsequently revised to be more negative. Two positive songs received ratings of 3.5 , and these were revised to be more positive. In the revisions, lyrics were changed to have more negative or positive themes. For one positive song, none of the participants detected an error. This error word was re-randomised to a different location in the song, and a new error word was chosen according to the guidelines outlined above. For all the other error words, at least two participants detected an error in each error song. The initial pilot test results were as predicted in the hypothesis - participants identified errors and non-errors better in the negative condition $(82.5 \%$ correct $)$, than in the positive condition $(72 \%$ correct $)$.

\subsection{Design}

In the online questionnaire, participants were informed that they were to be presented with 40, one minute songs - half positive-sounding, and half negative-sounding. They were told that some of the lyrics in the songs would have errors in them - words that do not fit into the context of the song. It was then explained that at the end of each song, they will be asked 1) was there an error in the lyrics? And 2) if there was an error, what was the error word? They were reminded that participation was voluntary and confidential, and that they were able to withdraw from the study at any time.

Before being presented with the experimental stimuli, participants were asked to play a neutral sound clip of a bell to ensure their audio equipment was working, and was adjusted to an appropriate volume. Demographic information was then collected.

To measure whether the stimuli were able to induce positive and negative moods in the participants, the PANAS was administered three times: before listening to any stimuli (baseline measure); after listening to the positive stimuli; and after listening to the negative 
stimuli. The PANAS is a 20 question measure of affect which consists of a 10 question positive affect scale and a 10 question negative affect scale, which are shown to be reliable, internally consistent, and uncorrelated with each other (Watson et al., 1988; APPENDIX D). The PANAS was chosen because it was a short measure of affect, and has been listed as one of the most used scales in studying musical emotions (Juslin \& Sloboda, 2010). Participants were asked to "indicate to what extent you feel this way right now, that is, at the present moment", when rating the different affect measures.

Participants were instructed to wear headphones, and to ensure their audio volume was at a comfortable level. It was emphasised that participants should only listen to each song once, and that they should listen to the whole song. If they weren't sure of an answer, they were told to guess.

The stimuli were presented in blocks of 20 songs. After the initial PANAS scale, the blocks were counterbalanced so that the participant was either presented with 20 positive songs, or 20 negative songs, to increase the likelihood of mood induction. Within these blocks, the songs themselves were randomised to counteract fatigue and practice effects. After each song participants were asked "Was there an error in the lyrics? If there was an error, please type the error word". Participants could then either select "Yes", and type in the error word, or "No".

After completing the experiment, participants were thanked for their time, and were told if they had listened to the negative songs last, to listen to a happy song to cheer themselves up. 


\subsection{Scoring System}

A scoring system was devised to encapsulate all possible answers. For a song with an error word, the highest rating was three points, and for a song without an error word, the highest rating was one point. Because the main point of interest was correct error word identification, and because the error word and no error word conditions weren't being compared, it did not matter that they had different highest possible ratings.

For the error word stimuli, when an error was present, a score of zero meant that the participant did not identify there was an error. A score of one meant that they identified an error, but either gave the wrong word or gave no answer. A score of two meant that they identified an error, and gave a word that rhymed with the error word (showing that the right word was identified, it was just misheard). A score of three meant that they identified an error, and they gave the correct error word (different spellings/phonetic spellings were accepted). For songs with no error, a score of zero was given if the participant said there was an error when there was not, and a score of one was given if the participant correctly said there was no error. This scoring system is shown in Table 1 . An overall positive and an overall negative error detection score was then calculated so that each participant had one score for positive error detection and one score for negative error detection.

Table 1

Scoring System

\begin{tabular}{lcccc}
\hline Condition & 0 & 1 & 2 & 3 \\
\hline Error & $\begin{array}{c}\text { Didn't } \\
\text { identify error }\end{array}$ & $\begin{array}{c}\text { Identified error, } \\
\text { gave wrong error word }\end{array}$ & $\begin{array}{c}\text { Answer rhymed } \\
\text { with error word }\end{array}$ & $\begin{array}{c}\text { Identified } \\
\text { correct error } \\
\text { word }\end{array}$ \\
No Error & $\begin{array}{c}\text { Incorrectly } \\
\text { identified error }\end{array}$ & $\begin{array}{c}\text { Correctly } \\
\text { identified no error }\end{array}$ & - & - \\
\hline
\end{tabular}




\section{RESULTS}

It was hypothesised that error words in negative songs would be more correctly identified than error words in positive songs, due to a more detailed, local level of cognitive processing being utilised when participants were in a more negative mood.

\subsection{Mood Scales}

To ensure the intended mood was induced, the mood ratings were compared. A repeated measures analysis of variance (ANOVA) was run on the initial positive and negative mood ratings (Base-Pos and Base-Neg); the mood ratings after the positive songs (Pos-Pos and Pos-Neg); and the mood ratings after the negative songs (Neg-Pos and Neg-Neg). The assumption of sphericity was violated, $\chi^{2}(14)=212.98, p=.0001$, so the Greenhouse-Geisser correction was applied. The ANOVA was significant, $F(1.81,113.74)=69.35, p=.0001, \eta^{2}$ $=.52$.

To see how the positive and negative stimuli affected mood ratings, planned pairwise comparisons were run. To control for family wise error, a Bonferroni corrected significance level of $\grave{a}=\alpha / \mathrm{c}$, was required; where $\mathrm{c}=$ number of comparisons made, and $\alpha=$ significance level. For the current comparison, $\grave{a}=.05 / 6$, as there were six comparisons being made. The required level of significance was therefore .008 . The positive ratings all differed significantly between conditions. The difference between Base-Pos $(M=26.61, S D=8.58)$ and Pos-Pos $(M=24.45, S D=9.49)$ was significant $t(64)=3.65, p=.001$, however positive mood decreased after positive songs compared to baseline, possibly due to effects of stimuli block (positive or negative first) randomisation. Base-Pos was significantly higher than Neg-Pos ( $M$ $=20.94, S D=8.56), t(64)=8.26, p=.0001$, and Pos-Pos was significantly higher than NegPos, $t(64)=4.56, p=.0001$. These comparisons suggest that positive mood decreased 
significantly after listening to negative stimuli, and that positive affect was lower after negative stimuli compared to after listening to positive stimuli.

None of the negative ratings were significantly different. As can be seen in Figure 2, the negative ratings appeared to show floor effects, with most of the changes occurring with the positive affect ratings. The difference between Base-Neg $(M=13.64, S D=4.80)$, and Pos-Neg $(M=12.55, S D=4.10)$, was non-significant, $t(64)=1.80, p=.08$, as was the difference between Base-Neg and Neg-Neg $(M=13.89, S D=4.58) ; t(64)=-.55, p=.59$. The difference between Pos-Neg and Neg-Neg came the closest to approaching significance, though with the conservative approach of controlling for family wise error, it too was nonsignificant, $t(64)=-2.57, p=.013$. It does appear that negative stimuli lowered positive affect, and therefore that the intended mood was induced. While there was not a similar effect shown with the negative scores, this is likely due to floor effects, as not much movement was possible.

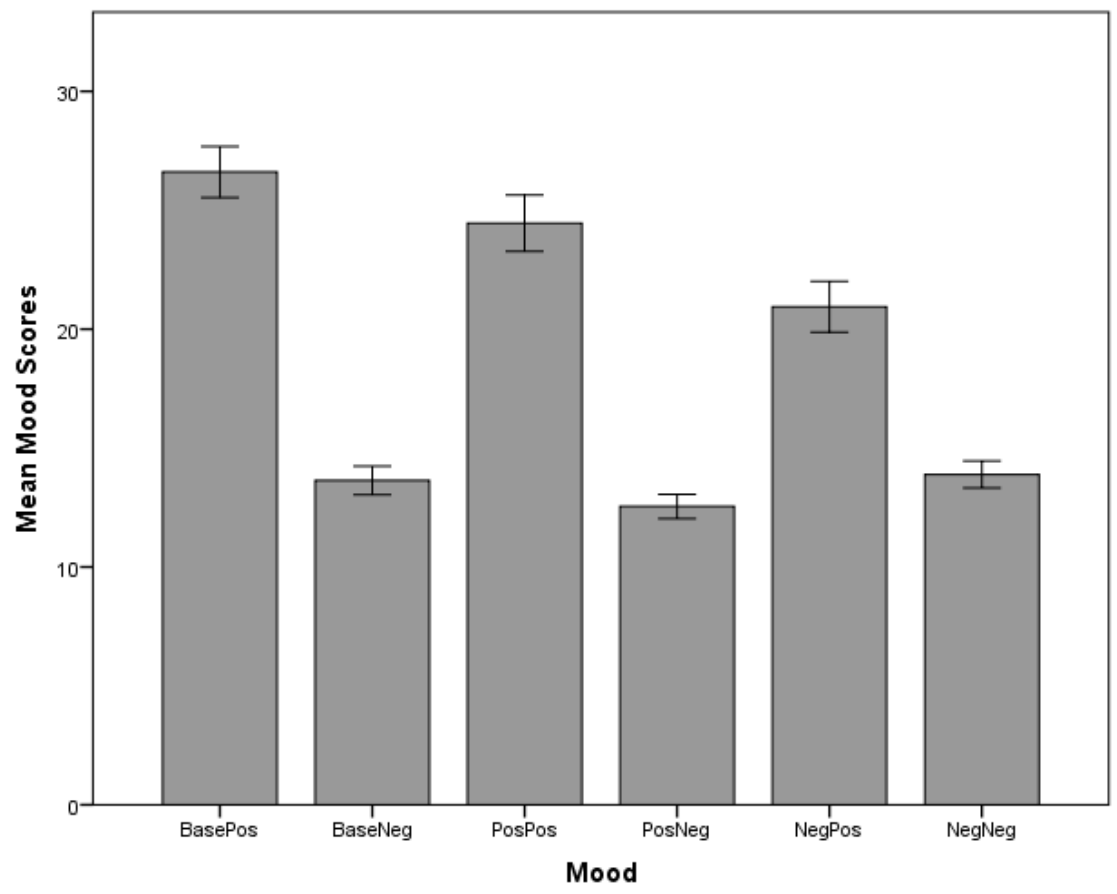

Figure 2: Mood ratings from PANAS at baseline, after positive songs, and after negative songs. Error bars represent mean standard error. 


\subsection{Positive and Negative Error Word Conditions}

Before running the ANOVA, the data was checked for normality of distribution in the total positive (TotalPos) and total negative (TotalNeg) conditions. The Kolmogorov-Smirnov test was run. Neither group distributions were significantly different from a normal distribution. For the total positive condition scores, $D(64)=.082, p=.20$, and for the total negative condition scores, $D(64)=.105, p=.080$. Data were also analysed visually to ensure normal distributions.

A repeated measures ANOVA was then run to test whether participants were more likely to recognise error words in the negative condition than in the positive condition. The total scores for positive and negative were compared (TotalPos and TotalNeg) and the difference was found to be significant, $F(1,63)=27.03, p=.0001, \eta^{2}=.30$. Figure 3 shows this graphically.

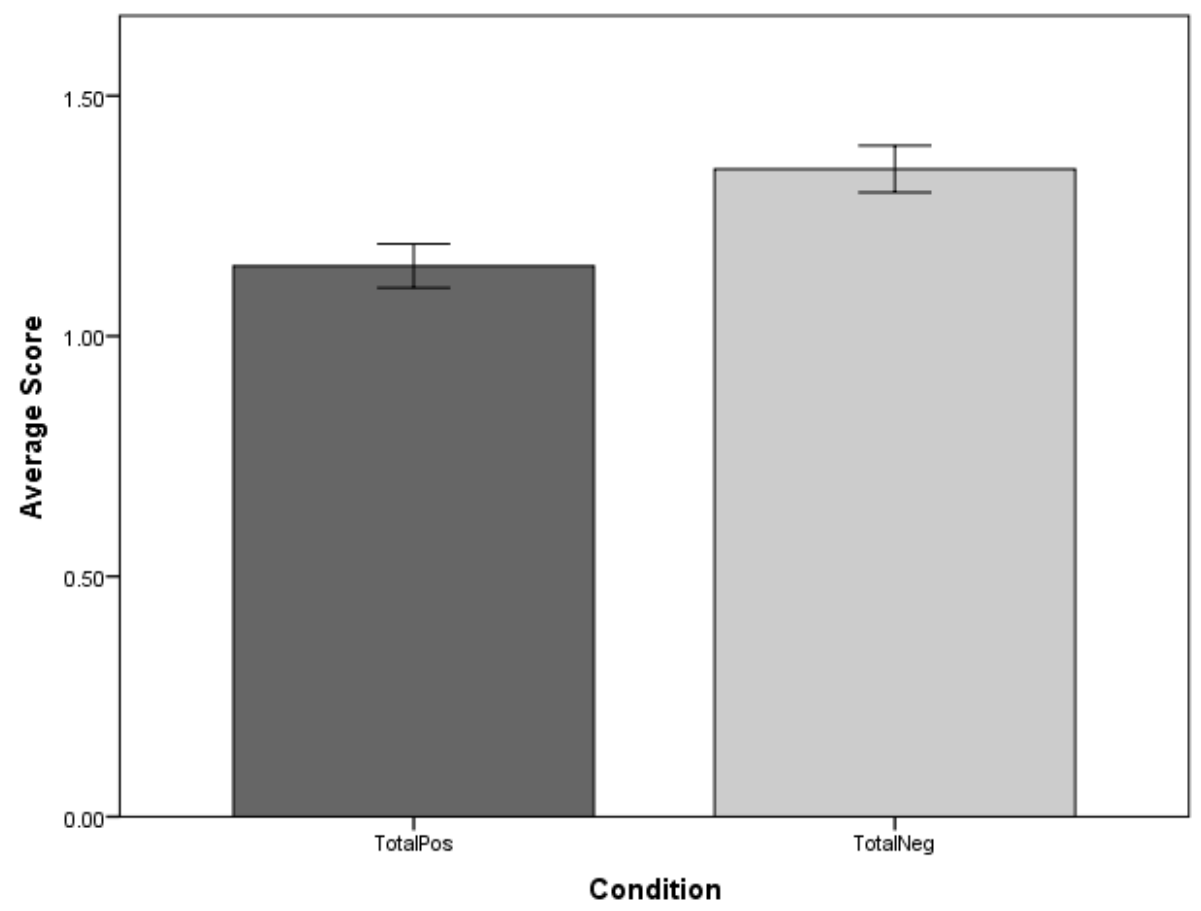

Figure 3: Positive and negative condition scores for all stimuli and all participants. Error bars represent mean standard error. 
To test whether false positives (reporting an error when there was no error) were more common in the positive or negative condition, the scores for songs with no error words were averaged for each participant. A repeated measures ANOVA was then run on the positive and negative scores for songs with no error (score of 1 = participant said there was no error; score of $0=$ participant said there was an error when there was not). The difference between the positive $(M=.88, S D=.14)$ and negative $(M=.94, S D=.09)$ conditions was significant: $F(1$, $63)=16.42, p=.0001, \eta^{2}=.21$ with participants giving false positive answers more often in the positive condition.

\subsection{Musical Ability}

A mixed design ANOVA was run with TotalPos and TotalNeg as the within-subject factors, and musical ability as the between-subjects factor. The initial analysis of the five groups of musicians: non-musician $(n=8)$, music-loving non-musician $(n=21)$, amateur musician $(n=24)$, semi-professional musician $(n=9)$, and professional musician $(n=2)$ showed no main effects of musical ability on error word detection, $F(4,59)=1.450, p=.23$, $\eta^{2}=.09$. Due to the small and uneven group sizes in these categories, participants were then grouped into either musician (amateur, semi-professional, and professional; $n=35$ ) or nonmusician (non-musician and music-loving non-musician; $n=29$ ). The same analysis using these groupings revealed a significant main effect of musical ability, $F(1,62)=4.261, p=.04$, $\eta^{2}=.06$, suggesting that musicians detected significantly less error words than non-musicians. This is shown in Figure 4. 


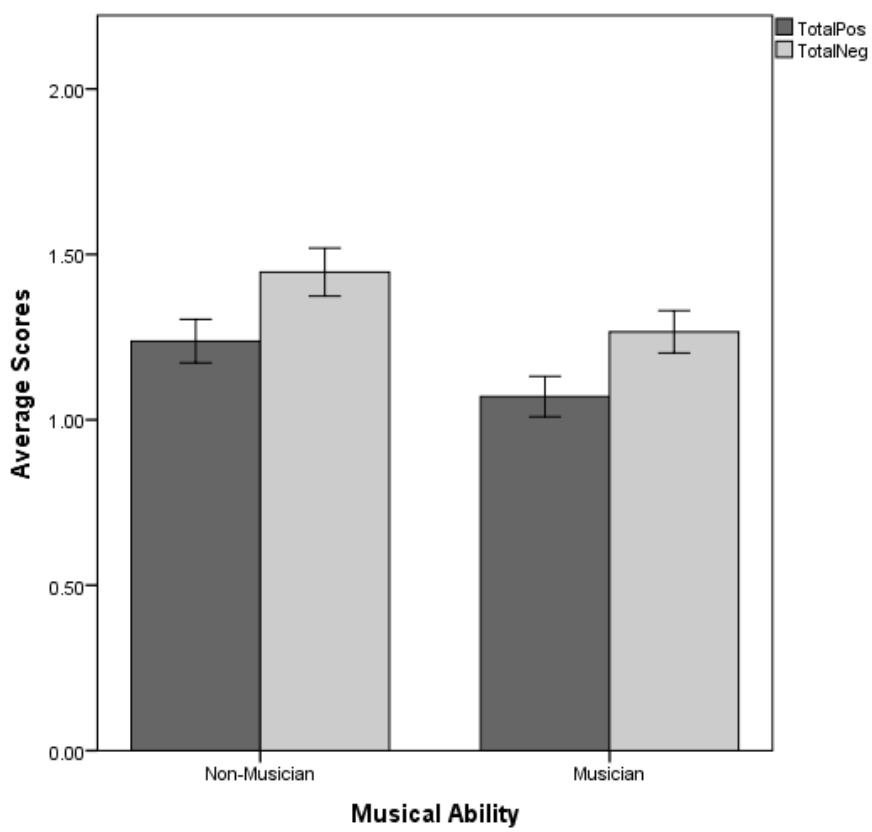

Figure 4: Scores for the negative and positive conditions depending on musical ability (non-musician or musician). Error bars represent mean standard error.

\subsection{Language and Fluency}

To see whether there was a difference between native English speakers and non-native English speakers, a mixed design ANOVA was run. Within subject factors were the scores for each condition (TotalPos and TotalNeg), and the between subject factor was linguistic background (Native English speaker, $n=41$; Non-native English speaker, $n=19$; Bilingual English speaker, $n=4)$. A main effect of language was found, $F(2,61)=6.671, p=.002, \eta^{2}=$ .18. This is shown in Figure 5. The same mixed design ANOVA was run with a betweensubjects factor of fluency (Fluent, $n=57$; Mostly Fluent, $n=7$ ). A main effect of fluency was also found, $F(1,62)=17.085, p=.0001, \eta^{2}=.22$. See Figure 6 . 


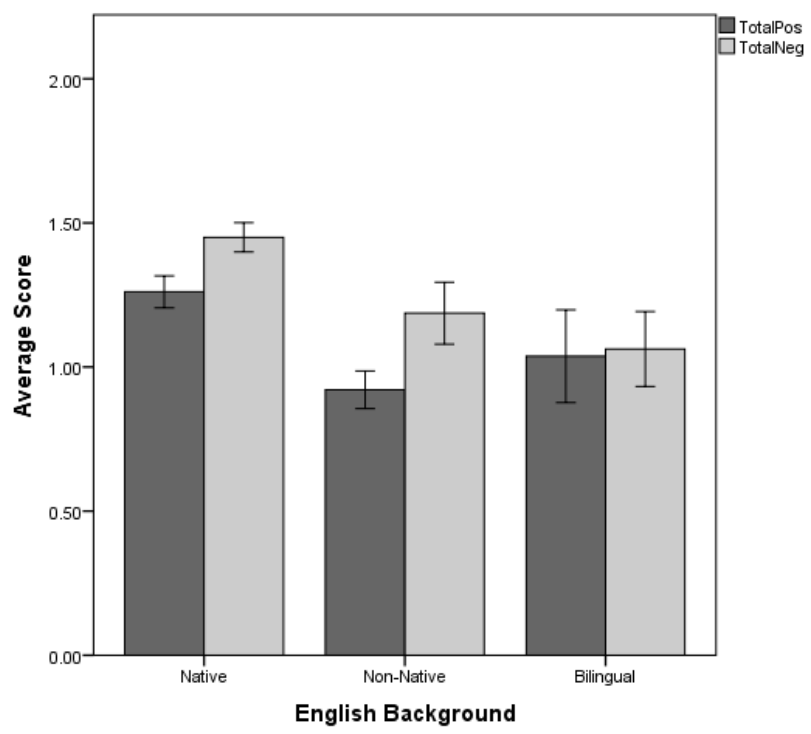

Figure 5: Scores for the negative and positive conditions depending on English speaking background. Error bars represent mean standard error.

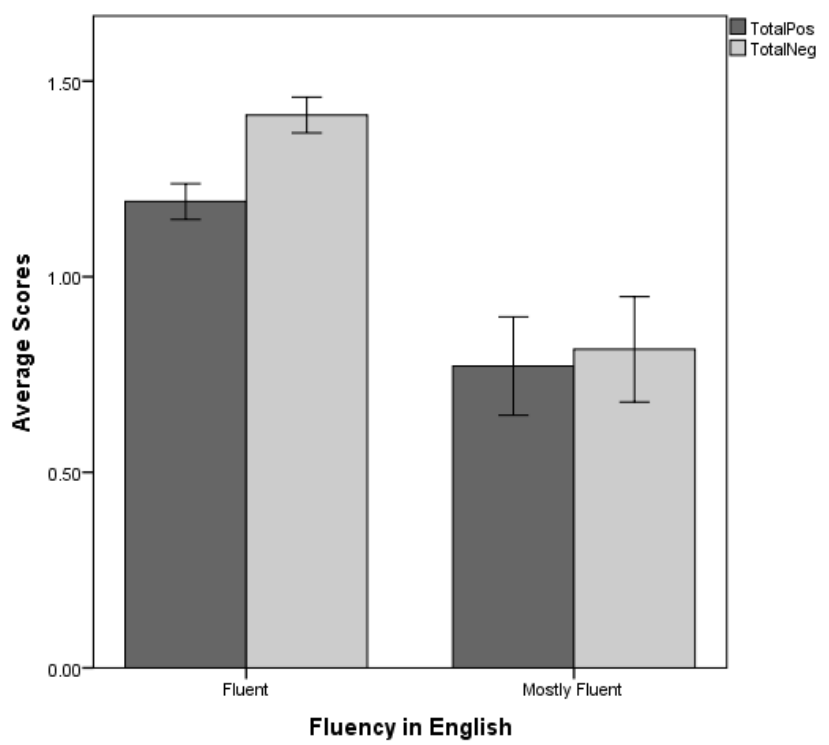

Figure 6: Scores for the negative and positive conditions depending on English fluency. Error bars represent mean standard error.

To see if there was a difference between non-native English speakers who rated themselves as 'fluent' $(n=12)$ compared to those who rated themselves as 'mostly fluent' ( $n$ $=7$ ), this data was examined individually. As seen in Figure 7, non-native English speakers who rated themselves as 'mostly fluent' showed little difference between the positive and 
negative conditions, due to floor effects of minimal error detection, however for non-native English speakers who rated themselves as 'fluent', the effect of condition seemed to be present. This was confirmed by running a repeated measures ANOVA on only data from 'fluent' non-native English speakers, which found a significant effect of condition: $F(1,11)=$ $16.385, p=.002, \eta^{2}=.60$. The same repeated measures analysis using the data of only the 'mostly fluent' non-native English speakers showed no significant effect of condition: $F(1,6)$ $=.61, p=.47, \eta^{2}=.09$. This suggests that the language level of participants who rated themselves as 'mostly fluent' was not high enough to detect semantic errors within the lyrics.

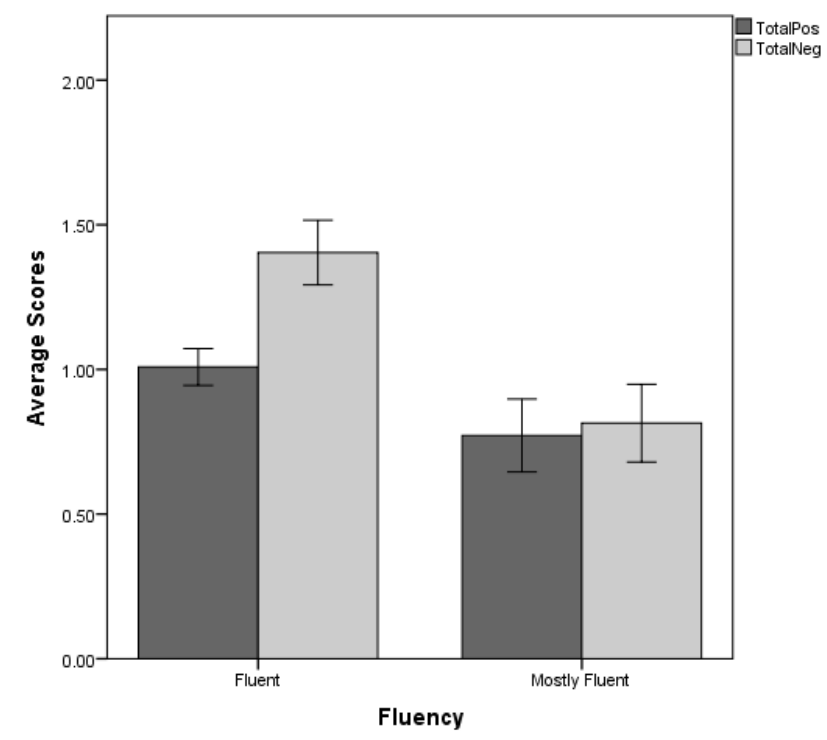

Figure 7: Scores for the negative and positive conditions depending on self report ratings of non-native English speaker's fluency. Error bars represent mean standard error.

To test whether the effect of condition was different for native English speakers compared to non-native English speakers who rated themselves as fluent, an independentsamples t-test was run. It was found that error detection in the negative condition did not differ significantly between native English speakers $(M=1.45, S D=.33)$ and fluent non- 
native English speakers $(M=1.40, S D=.39), t(51)=.41, p=.68$. Interestingly however, error detection in the positive condition did differ significantly between native English speakers $(M=1.26, S D=1.01)$ and fluent non-native English speakers $(M=1.01, S D=.22)$; $t(51)=2.32, p=.02$. This can be seen in Figure 8.

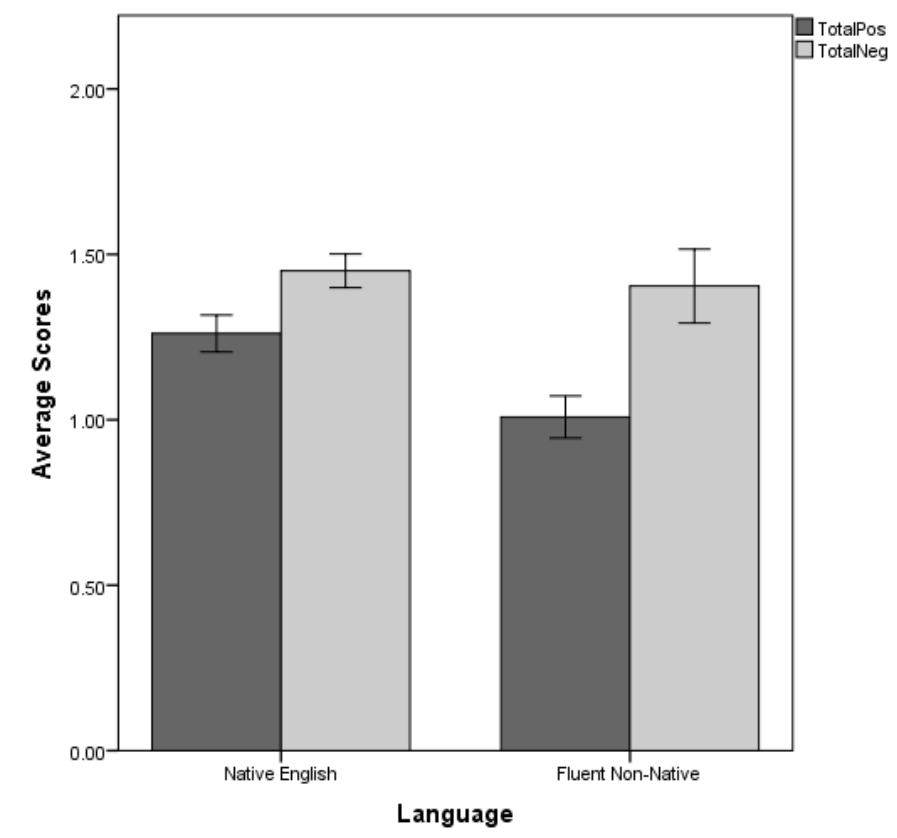

Figure 8: Scores for the negative and positive conditions for native English speakers, and non-native English speakers who rated themselves as fluent. Error bars represent mean standard error.

\subsection{The Stimuli}

While the overall result was that people were better able to detect errors in the negative condition, it is useful to see the spread of error detection over songs with an error in the lyrics to see whether the positive and negative condition stimuli were otherwise comparable. The spread of scores can be seen in Figures 9a and 9b. It can be seen that the range of scores (for the positive condition error songs only, $r=1.81$; for the negative condition error songs only, $r=1.94$ ) are comparable, and visually the two conditions have a similar distribution. This suggests that the level of difficulty and the variance within were 
similar, and thus that the effect was due to the condition (negative or positive), rather than a difference in difficulty for detecting error words.

a)

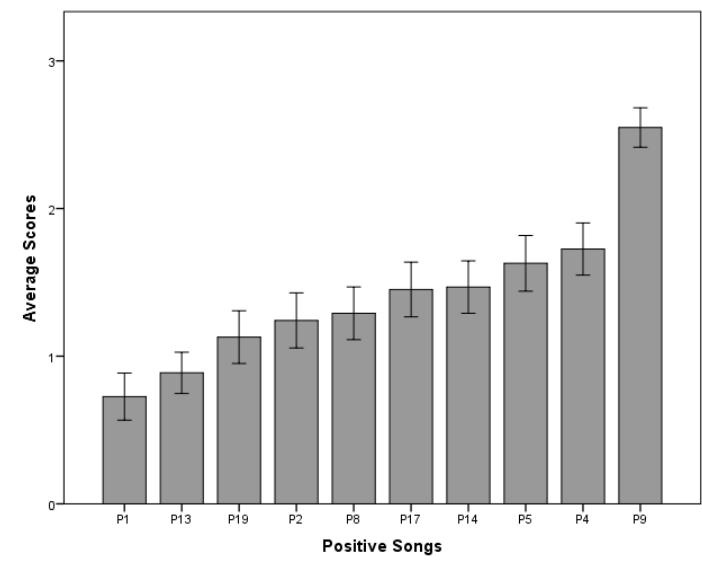

b)

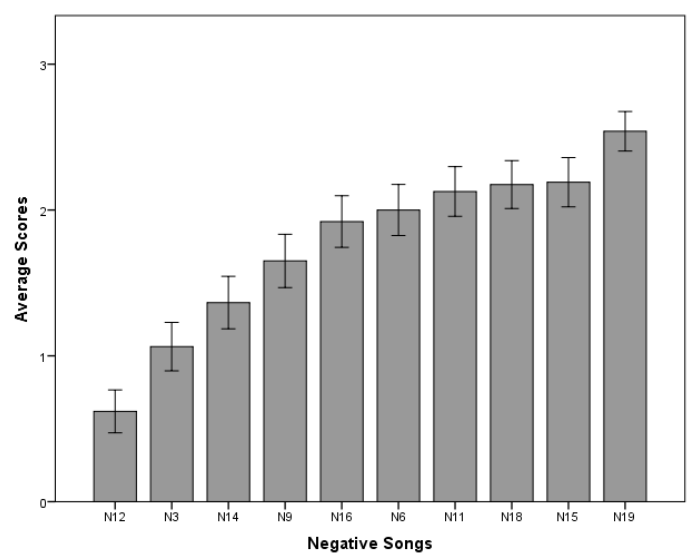

Figure 9: (a) Average scores on each song with an error in the positive condition; (b) average scores on each song with an error in the negative condition. Error bars represent mean standard error.

To further ensure that differences between groups were not due to differences in stimuli, an independent samples t-test was run for the word-count of the songs in each condition. It was found that the amount of words for songs in the positive $(M=55.15, S D=5.69)$ and negative $(M=55.2, S D=5.59)$ conditions were not significantly different: $t(38)=-.28, p=$ .98.

To check that the error word positions within the songs were not significantly different for the positive $(M=33.3, \mathrm{SD}=13.47)$ and negative $(M=27.4, \mathrm{SD}=15.01)$ conditions, an independent samples t-test was run, which was also not significant: $t(18)=.925, p=.37$.

To check that there was no effect of the error word's position in the sentence, a final independent samples t-test was run, which found no significant difference between the 
positions of words in a sentence in the positive condition $(M=4.1, S D=1.66)$ compared to the negative condition $(M=4.0, S D=2.05), t(18)=.12, p=.91$.

\section{DISCUSSION}

The current study tested and confirmed the hypothesis that detection of error words would be greater for lyrics paired with negative music compared to lyrics paired with positive music. This hypothesis was based on the feelings-as-information theory (Schwarz, 2010), previous research showing that lyrics affect listeners differently depending on the music they are paired with (Ali \& Peynircioğlu, 2006; Brattico et al., 2011), and research looking at the multitude of connections between music and language (Patel, 2008) and music and emotion (Juslin \& Västfjäll, 2008). In addition, it was found that there was a significant difference between musicians and non-musicians in error word detection, with non-musicians detecting more error words than musicians. Native English speakers also detected significantly more errors than non-native English speakers, and participants who rated themselves as 'fluent' in English detected significantly more errors than participants who rated themselves as 'mostly fluent'. These findings, as well as the implications and limitations of the study will be discussed.

\subsection{Feelings-As-Information Theory and Implications for Lyric Processing}

The finding that more error words were detected in the negative music condition is consistent with the feelings-as-information theory (Schwarz, 2010; also referred to as affectas-information theory; Storbeck \& Clore, 2007; Storbeck \& Clore, 2008), and suggests a role for musical mood in understanding processing connections between music and language. According to the feelings-as-information theory, our mood influences the way we process 
information in our environment. This theory suggests that when we are in a negative mood (in this case, listening to negative music), we are more likely to process information (in this case lyrics) in a more bottom-up, detail oriented, analytic, systematic and local level manner. Drawing on Brattico et al's. (2011) finding that when lyrics are paired with sad music they activate deeper semantic networks than when lyrics are paired with happy music, it is further hypothesised that the detail oriented processing induced by negative mood allows for a deeper integration and processing of lyrics when paired with negative music. The feelings-asinformation theory also states that when we are in a positive mood, information (lyrics in this case) is likely to be processed at a more global level, using heuristics and top-down processing, as well as with limited attentional focus. Since it was found in the current experiment that the negative condition corresponded with higher error detection, the implication is that different processing strategies are used to process lyrics depending on the valence of the music.

The current study suggests that musical valence determines the way song lyrics are processed and that we therefore engage with lyrics in a different way depending on the musical valence. This can help explain previous findings by Brattico et al. (2011) and Ali and Peynircioğlu (2006) who found differential effects of lyrics on mood depending on whether they were paired with positive or negative music. These previous studies were unable to satisfactorily explain the findings that sad lyrics were processed at a deeper level and enhanced emotion compared to happy lyrics with happy music. The current study strongly suggests that the reason sad lyrics with sad music lead to a greater feeling of sadness than happy lyrics with happy music lead to happiness is due to different processing techniques, and that any analysis or generalisations about how lyrics and music interact should take into consideration the musical valence of the song and differential processing of the lyrics. 
In addition to the main effect that participants detected more errors in the negative condition, it was also found that there were significantly more false positives reported in the positive condition. Paired with the information that participants were more accurate in the negative condition, this result is suggested to be due to heuristic processing causing participants to be more likely to guess in the positive condition, as they were not processing the information at a detailed level. This further supports the hypothesis that musical valence changes the way music is processed, and is similar to a study reported by Bless et al. (1996) which found that participants in a positive mood were more likely to use internal heuristics in remembering information and therefore were more likely to guess or report stimuli that did not occur. Participants in a negative mood, however, were found to more accurately report what occurred due to a more detailed initial processing of information. The finding that false positives occurred significantly more often in the positive condition therefore complements the current hypothesis that positive mood leads to lower levels of error detection than negative mood.

Such a finding can help with the interpretation of past studies with conflicting results about whether music or lyrics are more important in inducing mood. An early study by Sousou (1997) came to the conclusion that music was more influential for mood than lyrics, by looking at the average change of mood for sad lyrics paired with sad music and for happy lyrics paired with happy music. In line with the current study, as well as both Brattico et al. (2011), and Ali and Peynircioğlu (2006), Sousou (1997) found that sad lyrics paired with sad music led to a greater increase in sadness than happy music with happy lyrics and comparative happiness ratings. Because these scores were averaged before being analysed, however, it was found that there were no main effects of lyrics on mood induction, and that music was thus more effective at inducing mood. If the mood categories had been examined separately in the analysis, it is possible they would have found that lyrics were more 
influential in sad music - a result that was potentially overlooked. Research by Stratton and Zalanowski (1994) showed the opposite finding - that lyrics were more influential than music in mood induction. However the main experiment that showed this examined only easylistening music which was not put into mood categories, and which was 'ambiguous' in terms of musical mood. It therefore cannot be interpreted in relation to the current results. Such studies show the importance of controlling for musical mood when assessing the respective weights of lyrics and music.

\subsection{Connections between Affect and Cognition}

The current study supports theories suggesting that affect and cognition are inherently interrelated and integrated in the brain. Connections between affect and cognition are complex, and there are different schools of thought as to the connectivity between the two. The so-called 'classic' view in the literature is that affect and cognition are separate entities that can be activated individually without affecting each other (see Storbeck \& Clore, 2007 for a discussion). For example Zajonc (1980) suggests that "affect and cognition are under the control of separated and partially independent systems that can influence each other in a variety of ways, and that both constitute independent sources of effects in information processing" (p. 151). Such a view is reflected in traditional models of cognitive processing, whereby affect and cognition are considered independent, and affect is thought to precede cognition (Zajonc, 1980, 2000). Zajonc (2000) refers to ancient philosophical thought from philosophers such as Aristotle who distinguished passions from reason, and suggests that it is therefore clear that affect and cognition should be studied separately. Such views and subsequent theories Zajonc developed, however, have been overshadowed and replaced by a 
growing body of research showing a strong neurological coupling of affect and cognition (Forgas, 2008).

A number of researchers argue for the importance of studying affect and cognition as mutually influential domains. Duncan and Barrett (2007) argue against theoretical notions that affect and cognition are separate and suggest that this is a merely phenomenological distinction. They further suggest that affect is a form of cognition itself, as both affective and cognitive networks are connected via feedback loops so that affect effects cognition, and cognition effects affect. Davidson (2003) goes as far as to say that it is a sin of affective neuroscience to suggest that affect and cognition utilise separate neural pathways; while Storbeck and Clore (2007) suggest that affect may modulate cognition and that they should therefore be studied together as their effects on the brain cannot be separated. Storbeck and Clore (2007) list a number of examples to counter Zajonc's $(1980,2000)$ argument, and go on to list neuroimaging evidence that suggests the connections between affect and cognition are symbiotic, and that trying to separate the two or determine cause and effect is futile. Such discussions show the influence affect has on cognition, and vice versa, and give further weight to the idea that mood can influence cognitive processing style, as shown in the current experiment.

Effects of emotion on cognitive processing have been investigated primarily in the visual domain, and relatively few studies have investigated the effect of emotion on language processing (for exceptions see Jiménez-Ortega et al., 2012; Matovic, Koch, \& Forgas, 2014). While few studies have examined the effects of mood on auditory processing or music, a study by Bless et al. (1996) induced a happy or sad mood and then presented participants with an audio tape of a restaurant scene. After the participants listened to the tape they were then asked whether a number of different scenarios had occurred in the tape. Bless et al. (1996) found that participants in a positive mood were more likely to draw on internal 
representations of what would be expected in a typical restaurant scene, thereby

demonstrating use of heuristics as opposed to systematic processing. Such a study showing different processing styles of positive and negative mood for information presented in the auditory domain, as well as other studies looking at the effect of mood on persuasion (Schwarz, 2010; Schwarz, Bless, \& Bohner, 1991), suggest that mood influences cognitive processing in general, not just in the visual cortex (Schwarz, 2010). The current study adds evidence to the literature that similar attentional effects occur for information presented in the auditory domain, and in particular for lyric processing.

In relation to language processing, some recent work is suggesting that mood has an effect on the cognitive processing of language (Matovic et al., 2014). Matovic et al. (2014) presented happy and sad mood-primed participants with semantically ambiguous sentences, and found that participants in a negative mood were more likely to identify an ambiguous sentence compared to participants in a positive mood. It was further shown that participants in a negative mood attended more to the sentence and took significantly longer to respond to the question. In an extended experiment, they found that participants in a negative mood were also better able to recall the sentence itself. Matovic et al. (2014) analyse their results in terms of an assimilation/accommodation framework (Bless \& Fiedler, 2006). Such benefits for negative mood have been shown previously (Forgas, 2013), and the assimilation/accommodation theory appears quite similar to the feelings-as-information theory.

According to the assimilation/accommodation theory (Bless \& Fiedler, 2006), positive mood leads to assimilative processing, while negative mood leads to accommodative processing. This theory appears to be an extension of the feelings-as-information theory, in that information from the environment is used to decide whether it is safe to use internal schemas, thoughts, and expectations to interpret incoming information (positive mood), or 
whether there is danger in the environment which makes it necessary to more systematically analyse incoming information as it may differ from our expectations and internal representations (negative mood). This is then suggested to influence our processing strategies so that in a positive mood we are more likely to use heuristics, global level and top-down processing, and in a negative mood we are more likely to use systematic and bottom-up processing strategies (Bless \& Fiedler, 2006; Forgas, 2013; Matovic et al., 2014). A similar theory is GLOMO - the global versus local level processing model (F $\square$ rster \& Dannenberg, 2010) which posits that positive mood leads to global processing and negative mood leads to local level processing (among other factors). Such theories are very similar to the feelings-asinformation theory, and so the current results will continue to be interpreted in a feelings-asinformation framework. The important point to note, however, is that although they have different names and may vary on small details, feelings-as-information, affect-as-information, assimilation/accommodation, and GLOMO all suggest that positive and negative mood lead to different processing styles and they all concur as to what these styles are. This supports the current finding, and has implications for future research into music information retrieval.

\subsection{Music Information Retrieval Combining Lyric and Audio Information}

The use of lyrics in categorising music into different mood categories and genres has only recently been used in music information retrieval studies. The lack of earlier work combining lyrics with audio information has been suggested to be due to the difficulty in interpreting semantic meaning through lyrics, the numerous ways a semantic evaluation could be conducted, and the often inherent ambiguous and metaphorical nature of lyrics $(\mathrm{Hu}, \mathrm{Chen}$, \& Yang, 2009; Nishikawa, et al., 2011). While most studies show that the combination of lyric and audio information enhances categorisation of songs (Hu \& Downie, 2010a; Hu \& 
Downie, 2010b; Laurier, Grivolla, \& Herrera, 2008), lyrics appear to have differential effects depending on the mood category they belong to, and the analysis technique used by the researchers. Whether music or lyrics are more important, and the extent to which they help to predict mood categories thus varies quite dramatically in these early stages of research.

As the MIR techniques for analysing and combining lyric and audio information are still being developed, it would be useful to incorporate the current finding that lyric information is processed differently and affects people differently depending on the valence of the music. As negative lyrics appear to have a larger effect on mood and are processed at a deeper level than positive lyrics, this could perhaps be incorporated into mood categorisation - whereby the emotion of the lyrics in negative music would be weighted more than the emotion of the lyrics in positive music. Of course more research needs to be carried out to see whether these findings relate to other mood categories, perhaps those associated with Russel's (1980) arousal-valence spectrum. The current finding is therefore important to music information retrieval work in trying to automate a process which would reflect human perception, without using human input.

\subsection{Effects of Musical Ability}

The current experiment found that non-musicians were significantly better at detecting error words than musicians. This result can be interpreted in a number of ways. The first direction to explore is that cognitive processing abilities might be higher for non-musicians compared to musicians in this sample. There is still some debate in the literature about the effect of musical training on other cognitive, non-musical abilities. It has been found, however, that musical training is linked to increased verbal memory (Brandler \& Rammsayer, 2003; Franklin et al., 2008), and enhanced cognitive processing due to greater neural 
plasticity (Rodrigues, Loureiro, \& Caramelli, 2010). Brandler and Rammsayer (2003)

however, also found that, apart from increased verbal memory, musicians did not significantly outperform non-musicians in a number of other measures of general intelligence or processing speed. In fact, non-musicians performed significantly better than musicians on a number of intelligence scales. Their sample contained both high performing musicians, and nonmusicians who were studying subjects such as physics, psychology, and law. While Brandler and Rammsayer (2003) had some interesting speculations about musicians utilising a more global level processing style and being more intuitive as opposed to logical thinkers (which would also fit in with the current results), the type of intelligence tests used could be argued to be better suited to participants studying physics, law and psychology, rather than to high performing musicians. Their results should therefore be interpreted with caution. Overall, musical ability has been shown to have positive effects on other cognitive processing capacities and certainly not detrimental effects (Moreno \& Bidelman, 2014; Schellenberg, 2005). It is therefore likely that there is another factor which is influencing the current result.

Musical training has been shown to have widespread effects on brain activity, connectivity, and neural organisation. Gaser and Schlaug (2003) found that musicians had increased amounts of grey matter compared to non-musicians in visual-spatial, motor, and auditory regions of the brain. They suggested that while some of these differences may already be present at birth, the majority of the changes are likely to be due to effects of musical practice, learning and rehearsal. They found clear correlates between amount of grey matter and amount of practice time, suggesting that these brain areas are responding to musical input. Hyde et al. (2009) carried out a longitudinal study on children, and found that fifteen months of musical training led to changes in neural structure compared to the control group. They found correlations with increased musical skills and equivalent brain areas, showing the plasticity of the human brain, and that musical input has a direct effect on brain 
structure in children. Numerous other studies have shown similar effects of musical training on brain structure (Bermudez \& Zatorre, 2005; Oechslin, Van de Ville, Lazeyras, Hauert, \& James, 2013; Schlaug, Jänke, Huang, Staiger, \& Steinmetz, 1995; Schlaug, Norton, Overy, \& Winner, 2005; Schmithorst \& Wilke, 2002), suggesting the possibility that musicians and non-musicians reacted to the stimuli in the current experiment in different ways.

An explanation for the current result that musicians detected significantly fewer errors than non-musicians is that musicians were paying more attention to the music, and this affected how much attention they could give to processing the lyrics. Several studies have shown that musicians are more likely than non-musicians to notice aspects of the music in non-directed studies (when they weren't asked to pay attention to the music). For example, Wolpert (2000) carried out an experiment in which participants were presented with a song containing lyrics sung in a different key to the music. It was found that all the musicians (though the sample was only ten) noticed the key difference, whereas only five out of forty non-musicians noticed that the lyrics and music were in a different key. Differences between musicians and non-musicians have also been shown in neuroimaging work. Seung, Kyong, Woo, Lee, and Lee (2005) found that the same musical stimuli elicited increased cognitive reactions in musicians compared to non-musicians. They suggested that this was due to increased attention being paid to the musical stimuli. Furthermore, it was shown that there was a greater connection between the two hemispheres for musicians compared to nonmusicians. Koelsch, Schr $\square$ ger, and Tervaniemi (1999) found that musicians automatically processed pre-attentive information to a greater level than non-musicians. Combining the results of such studies, it is likely that while the instructions in the current experiment were to try and detect an error word (focus on the lyrics), musicians automatically diverted attention to the music, and therefore had lower error word detection scores. 


\subsection{Native English Speakers and Fluency}

The finding that native English speakers detected significantly more words than nonnative English speakers was as predicted. As the words were presented in English, and were sung by a native English speaker, it is likely that it was more difficult for non-native English speakers to understand the lyrics, and to realise when a sentence had a semantic error. This was further emphasised when fluency was taken into account. Non-native English speakers who rated themselves as 'mostly fluent' showed noticeable floor effects in error detection, and detected significantly fewer errors than non-native English speakers who rated themselves as 'fluent'. When non-native English speakers who rated themselves as 'fluent' were compared with native English speakers, an interesting result was found: there was a significant difference in error detection in the positive condition - fluent, non-native English speakers detected significantly fewer errors than native English speakers - however both native English speakers and fluent non-native English speakers detected a similar number of errors in the negative condition. This was unexpected, and could point to one of several explanations. Firstly, non-native English speakers may have found the words more difficult to understand or notice in the positive condition. Secondly, there may have been an effect of unequal group sizes for the native English speaking group compared to the fluent non-native English speaking group, or thirdly, it is possible that fluent non-native English speakers show more of an effect of mood induced cognitive processing.

While none of these explanations can be tested directly, it is useful to speculate about possible reasons behind the outcome. A number of comparisons were run between the positive and negative condition error words to ensure that the difficulty levels were as similar as possible. While this cannot be controlled for entirely due to the use of ecologically valid stimuli, the negative and positive condition error words were designed to be as similar as 
possible, so a difficulty effect is possible but unlikely. It is possible that the word presentation rate was faster in the positive condition due to the faster tempo. This could have made it more difficult for non-native English speakers to process or understand the error words. This will be discussed further in the considerations and limitations section, but is something to keep in mind when interpreting the results. As the group sizes were noticeably different (12 fluent non-native English speakers compared to 41 native English speakers), to see if this effect was due to anything other than sample effects a similar experiment should be run on a larger group of participants. As the first two options are unable to be controlled in the current experiment, it is interesting to speculate about potential differences in processing between fluent nonnative English speakers and native English speakers depending on mood induction.

While to the best of the author's knowledge no studies have specifically looked at the effects of induced mood on the processing of language in non-native English speakers, a number of studies have investigated differences in language processing between native speakers (L1) and non-native speakers (L2). Roberts and Felser (2011) suggest that, since syntactic processing is not as natural for L2 speakers (Clahsen \& Felser, 2006), L2 speakers are more likely to rely on semantic information while processing a sentence, and they are therefore very sensitive to semantic information. This would suggest that the fluent nonnative English speakers in the current study are just as sensitive to semantic errors as the nonnative English speakers (as seen with the same level of error detection in the negative condition), so that the effect is likely due to something other than semantic sensitivity differences. A number of studies have shown differences in language processing for L1 and L2 speakers, (Hahne, 2001; Minagawa-Kawai, Mori, \& Sato, 2005; Sanders \& Neville, 2003) so it is possible that the lyrics are being processed differently for L1 and L2 participants.

There is currently a debate about whether neural resources are shared between a person's first and second language, and whether these languages are processed in a similar 
manner. Heuven and Dijkstra (2010) present large bodies of research suggesting that there are both shared neural substrates and separate neural substrates for different languages in the brain. Heuven and Dijkstra (2010) provide further evidence showing that this can depend on the age of acquisition and level of proficiency of the participants. Pillai et al. (2003) looked at native Spanish speakers with English as a second language, and found differences between phonological (rhyming) and semantic (noun-verb association) processing depending on whether the language was native (Spanish) or non-native (English). They suggest that in the L2 language, the neural networks processing phonological information are more distinct from semantic processing compared to in the L1 language. They therefore suggest that while there are common neural circuits which process linguistic information, there are also distinct circuits which process a second language. There are two main ways this could relate to the findings in the current study. It could be that positive mood leads to a greater effect of global processing on non-native English speakers, or that negative mood leads to a greater effect of local level processing in non-native English speakers. Future research could investigate whether mood-induced processing styles affect L1 and L2 speakers in different ways.

Differences between native English speakers and non-native English speakers suggest that lyric information may not be processed to as great an extent when it is not in the native language of the listener. As music has been shown to have an effect on emotions and to be used for mood regulation (Juslin \& Västfjäll, 2008), it is important to keep in mind that music with lyrics in the listener's native language might be processed more deeply and have more of an effect on emotions than lyrics in the L2 language. This has indeed been shown in studies looking at L2 speakers' reaction to emotional words. Dewaele (2008) ran a large study on over 1000 people with 77 different native languages, and found that the expression of the phrase 'I love you' was considered stronger in their native language, suggesting the L2 language is not as deeply connected to emotional words. Caldwell-Harris and Ayçiçeği-Dinn 
(2009) found that participants showed less emotion (measured through skin conductance responses) to emotional words in their non-native language compared to their native language, and that they found it easier to lie in a second language. Dewaele (2004) also found that participants felt swearing in their native language was more forceful and emotional than in a second language. In these studies, age of acquisition and level of proficiency (among other things) influenced the outcome. Such studies suggest that linguistic emotional content has different effects on L1 and L2 speakers.

The current result that non-native speakers were significantly worse at detecting errors than native English speakers in the positive but not the negative condition, could be due to an interaction between processing speed and processing style. An interesting experiment by Opitz and Degner (2012) presented 100 negative words, 100 positive words, and 100 neutral words to participants in their L1 (French or German) and in their L2 language (French or German). They ran a lexical monitoring task where participants were asked to press a button when presented with a pseudo word while event related potentials were recorded. Opitz and Degner (2012) found that there was no difference in the way the words were processed between L1 and L2 speakers, but that L2 speakers of the language processed emotional words significantly slower than native speakers. This finding is supported by previous research showing that semantic violations were processed more slowly in L2 languages (Hahne, 2001), and a number of EEG studies showing a delay in semantic processing for the L2 language (e.g. Moreno, Rodriguez-Fornells, \& Laine, 2008).

In relation to these findings by Opitz and Degner (2012) and Hahne (2001), it can be hypothesised that non-native English speakers are slower to process the words, and when this is combined with a global level, heuristic-based processing style, this could lead to lower error detection. As the lyrics were presented aurally and in real-time, it is possible that nonnative English speakers employing a heuristic processing style did not attend to or encode the 
words effectively, and so by the time they had realised there may have been an error, it was too late to detect it. This is reflected in non-native English speakers detecting significantly fewer errors in the positive condition than native English speakers. On the other hand, the local level, detail oriented processing style utilised for the negative lyrics could mean nonnative English speakers are more likely to pick up on these errors, even when their processing time is slower, as the words were encoded in more detail to begin with. Of course this same effect could occur due to the speed of lyrics, as it is possible words were presented faster in the positive condition compared to the negative condition. Either way, this result shows a possible reflection of non-native English speakers' slower processing speed in the L2 language.

The current finding and research showing different influences of words in L2 languages have implications for music therapy. Language has been shown to play a role in the therapeutic environment through dual identities and a second language being able to distance the client from the emotional side of what they are saying (Santiago-Rivera \& Altarriba, 2002). If music therapists are aware that negative music is more likely to engage the client's deeper semantic pathways (Brattico et al., 2011), and have lyrics resonate at a deeper level than in positive music, this could be used as a therapeutic tool. If a music therapist is working with a client with a different native language, it might be useful to have them listen to and create lyrics in their own language, as this is likely to have more of an emotional impact, and is more likely to be expressive of their real thoughts (Santiago-Rivera \& Altarriba, 2002). While the current study was focused mainly on the cognitive processing of lyrics under different mood induced states, the linguistic and emotional nature of the current stimuli and the differences found between native and non-native English speakers is interesting and relevant to music therapy practice. Further research is warranted to investigate whether there is an effect of mood on language processing which differs depending on native language. 


\subsection{Semantics}

The current experiment investigated how lyrics are processed depending on the music they are paired with. While there has been a large focus on 'information processing' in general, the type of information being processed is of a semantic nature. To detect an error, the listener had to parse the sentence, and register that there was a word that did not make sense within the context of the song and sentence. This involves semantic processing. The current experiment was inspired by work suggesting that lyrics with negative music are processed at a deeper semantic level and activated more language areas in the brain than lyrics with positive music, suggesting that there was a differential effect of emotion on semantic processing (Brattico et al., 2011). This is further supported by event-related potential studies showing that induced mood can affect the way semantic information is processed on-line (Federmeier et al., 2001). The results of the current experiment suggest that negative lyrics paired with negative music engage different processing strategies compared to positive lyrics and positive music because we are more likely to process the negative lyrics with a more local, detailed, integrated processing style.

An interesting experiment by Bolte, Goschke, and Kuhl (2003) could provide a different interpretation of the current findings. Bolte et al. (2003) induced positive or negative moods, and then presented participants with word triads. The task was to guess quickly whether the three words were semantically related to another word. Bolte et al. (2003) found that positive mood led to a quicker and more accurate response. They suggest that this occurs because positive mood allows for a greater activation of associative networks than negative mood, and participants are therefore able to activate semantic information more quickly. In terms of the current experiment, this could suggest that when in a positive mood, participants did not detect as many error words because they were more likely to find them acceptable in 
the context of the music, due to wider associative networks being activated. This is not supported by neuroimaging evidence showing greater activation of language areas with sad music and lyrics (Brattico et al., 2011), and does not explain the finding that people in a positive mood reported significantly more false positives (said there was an error when there was not) than participants in a negative mood. The false positive finding could suggest that participants in a positive mood were using heuristic processing, and therefore were more likely to guess if there was an error word as opposed to those in a negative mood who had processed the information more carefully. Bolte et al.'s (2003) study could also be interpreted within a feelings-as-information framework, wherein participants in a negative mood were less likely to make heuristic, quick, intuitive decisions, and therefore scored worse than those in a positive mood.

\subsection{Considerations and Limitations}

An important consideration in this design is whether the speed of the lyrics (related to the bpm) of the song affected error detection. As positive music is characterised by fast tempo and major key, and negative music is characterised by slow tempo and minor key (Juslin \& Laukka, 2004), this potential confound could not be avoided while retaining the ecological validity and strong distinctions between positive and negative stimuli. It is possible that positive songs resulted in lower error detection, merely because the words were sung faster due to the faster tempo. To control for this, the average number of words in each condition were kept equal. Both positive and negative songs had an average of 55 words, and were all approximately one minute in length, with approximately a 15 second music-only introduction. Keeping a similar number of lyrics between conditions was chosen instead of changing the tempo of the pieces, as studies have shown that a major defining feature of positive songs is 
an upbeat tempo, and for negative songs, a slower tempo (Gomez \& Danuser, 2007; Juslin \& Laukka, 2004), and that when these cues are mixed, emotion induction is likewise altered (Hunter, Schellenberg, \& Schimmack, 2010). While the rate of presentation of lyrics could not be controlled for entirely, it was controlled for as well as possible in the current circumstances.

Also important to the current study is the complexity of the arousal/valence spectrum. A form of the arousal/valence spectrum called the circumplex model of affect was put forward by Russell (1980). Russell (1980) suggested arousal and valence (he originally called it pleasure) exist in a three dimensional space where arousal (high to low) is on the y-axis, and valence (negative to positive) is on the x-axis. Much psychological work on emotions has used this dimensional model and it has become very influential in the literature (Eerola \& Vuoskoski, 2011). While valence was deliberately manipulated and is the focus of the current experiment, arousal was not controlled for. While arousal and valence have been shown to activate different areas of the brain (Anders, Lotze, Erb, Grodd, \& Birbaumer, 2004; Lewis, Critchley, Rotshtein, \& Dolan, 2006), it has also been shown that both arousal and valence influence and interact with each other (McConnell \& Shore, 2011). As it has been shown that faster tempo leads to increased arousal, whereas slower tempo leads to decreased arousal (Husain, Thompson, \& Schellenberg, 2002), it may be hypothesised that the faster tempo songs (positive stimuli) would lead to increased arousal, whereas the slower tempo songs (negative stimuli) would lead to decreased arousal. If this is the case, and it is as straight forward as higher arousal resulting in improved cognitive processing (Husain et al., 2002), then the current result is even more likely to be a real effect of negative mood increasing local level processing, as the higher arousal in the fast tempo positive music would be thought to heighten attention to error words. Of course considering the negative valence within the negative songs, this could also have lead to increased arousal due to subject matter. Short of 
asking participants to rate their arousal and valence levels after each song, this is difficult to ascertain. Future research should control both arousal and valence, and have participants rate felt levels of arousal and valence in the music.

The interactions between arousal and valence appear quite varied and difficult to interpret, and studies have had inconclusive findings as to their interactions, possibly based on uncontrolled variables (Day, Lin, Huang, \& Chuang, 2008; Jefferies, Smilek, Eich, \& Enns, 2008; McConnell \& Shore, 2011). Future studies with a similar goal in mind would therefore benefit from a control of arousal as well as valence. With the ecologically valid stimuli in the current experiment however, this was difficult to do. Future research should also ask participants to rate their arousal and valence levels after each song to see whether these ratings are correlated with error word detection, or cognitive processing in general. Much of the research investigating effects of arousal and valence on cognitive processing has not been carried out in the auditory domain, but in the visual domain using spatial tasks (Husain et al., 2002), attentional tasks (alerting, orienting, executive control; McConnell \& Shore, 2011), and visual decision making tasks (Day et al., 2008). While the effects of arousal and valence on cognition are likely to be similar in both domains, this is an important factor to keep in mind. While the current experiment can suggest that negatively valenced music leads to increased error word detection, it cannot make statements about arousal. This should be included in future research.

To control variability, ensure the songs had not been heard before, and to seamlessly incorporate error words into the lyrics, the songs were written, performed and recorded by the author. While this was useful to keep all the stimuli similar and to control tempo, key, voice, and timbre, this could also have affected the results. The words were sung with an Australian accent, which could have benefitted Australian participants. As the experiment was investigating the ratio of error words detected in positive and negative songs, this should not 
have had an effect within subjects however. Furthermore, as the songs were all performed on acoustic guitar, they had a folk music feel to them. As musical preference was not assessed, it is possible that musical preferences affected how much attention people paid to the music. While this should not have an effect within subjects, it could have been a factor when looking at the differences between musicians and non-musicians, or with non-native and native English speakers. As the literature suggests that musical preference affects the way emotion is induced and how we interact with music (Kreutz, Ott, Teichmann, Osawa, \& Vaitl, 2008), future research should incorporate musical preferences to see if this has an impact on cognitive processing and/or attention.

The questionnaire was distributed in an online format to recruit the maximum number of participants. While this was convenient, the experiment was not conducted in a laboratory setting, and there were likely differences between the equipment participants used to listen to the stimuli. A high percentage of participants reported using headphones; however the quality of the headphones and the volume of stimuli presentation could not be controlled by the experimenter. While it was strongly suggested that participants only listen to each song once, it was also possible that participants listened to the songs more than once. This could not be controlled due to the survey design. However if certain participants did listen to songs more than once, it is hopeful that they were consistent between the positive and negative stimuli. Due to the automatic randomisation of the positive and negative blocks, it was unable to be ascertained from the results which block each participant was presented with first. This knowledge would have been useful in assessing the effect of the stimuli on mood. As negative mood has been shown to be more powerful and processed more deeply than positive mood (Baumeister, Bratslavsky, Finkenauer, \& Vohs, 2001) it is possible that there were carry over effects for participants who listened to the negative stimuli first. This is suggested from the 
mood induction results. This cannot be confirmed however due to the use of automatic randomisation through Qualtrics.

The PANAS mood scale was used to assess mood at baseline level, after positive stimuli, and after negative stimuli. The PANAS is a short assessment of mood which has high reliability and internal consistency, and is often used in mood research (Watson et al., 1988), and research into musical emotions (Juslin \& Sloboda, 2010). While the results did show significant effects of stimuli on mood, there appeared to be floor effects on the negative scale, as negative affect ratings stayed consistently close to the zero point. There were much higher ratings and variability within the positive affect ratings, suggesting that: positive mood was affected by the stimuli to a greater extent than negative mood; that the participants in this sample had high positive affect; or that the scale was not a good measure for negative transient mood states. As some researchers have suggested that emotions induced by music should not be rated on the same measures as emotions induced through other means (Vusokoski \& Eerola, 2011), this could also have been a factor. Music specific emotion scales (such as GEMS) were not used because their suitability for music with lyrics has not been ascertained. A well tested, general mood scale was therefore seen as the most appropriate measure. Future research should use a scale that is more sensitive to negative musical emotions in particular. The development of a measure of musical emotions which has been validated with lyrics is also advised. A number of participants mentioned that the negative songs made them feel quite sad, so a measure of affect which reflects this would be useful.

\subsection{Conclusion}

The current experiment supports studies showing that lyrics are processed differently depending on the music they are paired with (Ali \& Peynircioğlu, 2006; Brattico et al., 2011), 
and further suggests that this is due to the use of different processing styles, in line with the feelings-as-information theory (Schwarz, 2010). The hypothesis that negative music leads to increased detection of semantic errors in lyrics compared to positive music was supported, and it is suggested that this is due to negative music inducing negative mood, and therefore activating a more systematic, local level, detail-oriented processing style (Schwarz, 2010). Positive mood on the other hand is suggested to employ a more heuristic-based, global level processing style, which is hypothesised to be the reason fewer error words were detected. This is further seen with a significantly higher number of false positives in the positive condition suggested to be due to participants being more likely to guess due to global level processing.

Significant differences were found between musicians and non-musicians, as well as between native and non-native English speakers, especially in relation to fluency. Musicians detected significantly fewer error words than non-musicians. This is suggested to be due to musicians attending more to the music than non-musicians, and therefore not paying as much attention to the lyrics. Native English speakers detected significantly more error words than non-native English speakers, which was as expected considering the nature of the task. There was a significant difference between non-native English speakers who rated themselves as 'fluent' compared to those who rated themselves as 'mostly fluent', with the mostly fluent group detecting significantly fewer error words and showing floor effects of error detection. Interestingly, there was a significant difference in error detection between fluent non-native and native English speakers only in the positive condition, but not in the negative condition. This warrants future research to see whether mood has a differential effect on language processing depending on native language.

There are a number of directions for future research which could be informed by the current experiment. Future research should expand the current findings by looking at more mood categories to better understand the connections between lyrics, mood, and music. It 
would also be valuable to incorporate arousal into future research to better understand the complexities of the arousal-valence spectrum and how this relates to lyrics and music. With the current results being found with ecologically valid stimuli, it might be useful to more thoroughly control the arousal and valence aspects of each song and see how this relates to lyric processing more specifically, so weightier conclusions can be drawn about cognitive processing based on arousal and/or valence. It would also be interesting to carry out a similar study using fMRI to examine whether deeper semantic pathways are indeed activated while processing negative music and lyrics as was seen in Brattico et al.'s (2011) study, and to extend these findings to different mood categories. Future research should also employ a more appropriate mood scale, as the PANAS mood scale appeared to show floor effects for negative affect. Larger samples doing similar experiments using fMRI would help to cement the theory that lyrics are processed differently depending on musical valence. This is important as the current findings have valuable implications for various fields, including MIR, music therapy, music and language research, as well as general music use and understanding.

The current findings have implications for understanding the complex interactions between mood, lyrics, and cognitive processing, and show the importance of mood in understanding connections between music and language. 


\section{REFERENCES}

Ali, S. O., \& Peynircioglu, Z. (2006). Songs and emotions: Are lyrics and melodies equal partners? Psychology of Music, 34, 511-534.

Alluri, V., Toiviainen, P., Jääskeläinen, I., Glerean, E., Sams, M., \& Brattico, E. (2012). Large-scale brain networks emerge from dynamic processing of musical timbre, key and rhythm. NeuroImage, 59, 3677-3689.

Anders, S., Lotze, M., Erb, M., Grodd, W., \& Birbaumer, N. (2004). Brain activity underlying emotional valence and arousal: A response-related fMRI study. Human Brain Mapping, 23, 200-209.

Baumeister, R., Bratslavsky,E., Finkenauer, C., \& Vohs, K. (2001). Bad is stronger than good. Review of General Psychology, 5, 323-370. doi: 10.1037//1089-2680.5.4.323

Baumgartner, T., Esslen, M., \& Jänkcke, L. (2006). From emotion perception to emotion experience: Emotions evoked by pictures and classical music. International Journal of Psychophysiology, 60, 34-43.

Bermudez, P., \& Zatorre, R. (2005). Differences in gray matter between musicians and nonmusicians. Annals of the New York Academy of Sciences, 1060, 395-399. doi: 10.1196/annals. 1360.057

Besson, M., Chobert, J., \& Marie, C. (2011). Transfer of training between music and speech: Common processing, attention and memory. Frontiers in Psychology, 2, 1-12.

Besson, M., Faita, F., Peretz, I., Bonnell, A., Requin, J. (1998). Singing in the brain: Independence of lyrics and tunes. Psychological Science, 9, 494-498.

Beukeboom, C., \& Semin, G. (2006). How mood turns on language. Journal of Experimental Social Psychology, 42, 553-566.

Bidelman, G. M., Gandour, J. T., \& Krishnan, A. (2011). Cross-domain effects of music and language experience on the representation of pitch in the human auditory brainstem. Journal of Cognitive Neuroscience, 23, 425-434.

Bless, H., Clore, G., Schwarz, N., Golisano, V., Rabe, C., \& W $\square$ lk, M. (1996). Mood and the use of scripts: Does a happy mood really lead to mindlessness? Journal of Personality and Social Psychology, 71, 665-679.

Bless, H., \& Fiedler, K. (2006). Mood and the regulation of information processing and behavior. In J.P. Forgas (Ed.), Affect in social thinking and behavior (pp.64-84). New York: Psychology Press.

Bolte, A., Goschke, T., \& Kuhl, J. (2003). Emotion and intuition: Effects of positive and negative mood on implicit judgments of semantic coherence. Psychological Science, $14,416-421$.

Brandler, S., \& Rammsayer, T. (2003). Differences in mental abilities between musicians and non-musicians. Psychology of Music, 31, 123-138. doi:10.1177/0305735603031002290

Brattico, E., Alluri, E., Bogert, B., Jacobsen, T., Vartiainen, N., Nieminen, S., \& Tervaniemi, M. (2011). A functional MRI study of happy and sad emotions in music with and without lyrics. Frontiers in Psychology, 2, 1-16.

Caldwell-Harris, C., \& Ayçiçeği-Dinn, A. (2009). Emotion and lying in a non-native language. International Journal of Psychophysiology, 71, 193-204. doi:10.1016/j.ijpsycho.2008.09.006

Clahsen, H., \& Felser, C. (2006). Grammatical Processing in Language Learners. Applied Psycholinguistics, 27, 3-42.

Coltheart, M. (1981). The MRC psycholinguistic database. The Quarterly Journal of Experimental Psychology. Section A: Human Experimental Psychology, 33, 497-505. 
Davidson, R. (2003). Seven sins in the study of emotion: Correctives from affective neuroscience. Brain and Cognition, 52, 129-132. doi:10.1016/S0278-2626(03)000150

Day, R., Lin, C., Huang, W., \& Chuang, S. (2008). Effects of music tempo and task difficulty on multi-attribute decision-making: An eye-tracking approach. Computers in Human Behavior, 25, 130-143.

Dewaele, J. (2004). Blistering barnacles! What language do multilinguals swear in?! Estudios de Sociolinguistica, 5, 83-105.

Dewaele, J. (2008). The emotional weight of "I love you" in multilinguals' languages. Journal of Pragmatics, 40, 1753-1780.

Downie, S. (2003). Music information retrieval. Annual Review of Information Science and Technology, 37, 295-340.

Drace, S. (2012). Evidence for the role of affect in mood congruent recall of autobiographic memories. Motivation and Emotion, in press.doi: 10.1007/s11031-012-9322-5.

Duncan, S., \& Barrett, L. (2007). Affect is a form of cognition: A neurobiological analysis. Cognition \& Emotion, 21, 1184-1211. doi: 10.1080/02699930701437931

Edigi, G., \& Gerrig, R. (2009). How valence affects language processing: Negativity bias and mood congruence in narrative comprehension. Memory \& Cognition, 37, 547-555.

Edigi, G., \& Nusbaum, H. (2012). Emotional language processing: How mood affects integration processes during discourse comprehension. Brain \& Language, 122, 199210.

Eerola, T., \& Vuoskoski, J. (2011). A comparison of the discrete and dimensional models of emotion in music. Psychology of Music, 39, 18-49. doi: 10.1177/0305735610362821

Ekman, P. (1992). Are there basic emotions? Psychological Review, 99, 550-553.

Ekman, P. (1999). In T. Dalgleish and M. Power (Eds.) Handbook of Cognition and Emotion. Sussex, U.K.: John Wiley \& Sons, Ltd., 1999.

Federmeier, K., Kirson, D., Moreno, E., \& Kutas. (2001). Effects of transient, mild mood states on semantic memory organization and use: An event-related potential investigation in humans. Neuroscience Letters, 305, 149-152.

Fiveash, A., \& Pammer, K. (2014). Music and language: Do they draw on similar syntactic working memory resources? Psychology of Music, 42, 190-209. doi: $10.1177 / 0305735612463949$

Forgas, J. (2008). Affect and cognition. Perspectives on Psychological Science, 3, 94-101. doi: $10.1111 / \mathrm{j} .1745-6916.2008 .00067 . \mathrm{x}$

Forgas, J. (2013). Don't worry, be sad! On the cognitive, motivational, and interpersonal benefits of negative mood. Current Directions in Psychological Science, 22, 225-231. doi: $10.1177 / 0963721412474458$

Förster, J., \& Dannenberg, L. (2010). GLOMO ${ }^{\text {sys }}$ : A systems account of global versus local processing. Psychological Inquiry: An International Journal for the Advancement of Psychological Theory, 21, 175-197. 10.1080/1047840X.2010.487849

Franklin, M.S., Moore, K.S., Yip, C., Jonides, J., Rattray, K., \& Moher, J. (2008). The effects of musical training on verbal memory. Psychology of Music, 36, 353-365. doi:10.1177/0305735607086044

Gaser, C., \& Schlaug, G. (2003). Brain structures differ between musicians and nonmusicians. The Journal of Neuroscience, 23, 9240-9245.

Gasper, K., \& Clore, G. (2002). Attending to the big picture: Mood and global versus local processing of visual information. Psychological Science, 13, 34-40.

Gomez, P., \& Danuser, B. (2007). Relationships between musical structure and psychophysiological measures of emotion. Emotion, 7, 377-387. 
Gordon, R., Schön, D., Magne, C., Artésano, C., \& Besson, M. (2010). Words and melody are intertwined in perception of sung words: EEG and behavioural evidence. PLoS ONE, 5, e9889.

Hagoort, P. (2003). Interplay between syntax and semantics during sentence comprehension: ERP effects of combining syntactic and semantic violations. Journal of Cognitive Neuroscience, 15, 883-899.

Hahne, A. (2001). What's different in second-language processing? Evidence from eventrelated brain potentials. Journal of Psycholinguistic Research, 30, 251-266.

Heuven, W., \& Dijkstra, T. (2010). Language comprehension in the bilingual brain: FMRI and ERP support for psycholinguistic models. Brain Research Reviews, 64, 104-122.

Hu, Y., Chen, X., \& Yang, D. (2009). Lyric-based song emotion detection with affective lexicon and fuzzy clustering method. In $10^{\text {th }}$ International Society for Music Information Retrieval Conference, ISMIR.

Hu, X., \& Downie, J. S. (2010a). Improving mood classification in music digital libraries by combining lyrics and audio. In JCDL (pp. 159-168).

$\mathrm{Hu}, \mathrm{X} .$, \& Downie, J. S. (2010b). When lyrics outperform audio for music mood classification: A feature analysis. $11^{\text {th }}$ International Society for Music Information Retrieval Conference (ISMIR 2010). 619-624.

Hunter, P., Schellenberg, G., \& Schimmack, U. (2010). Feelings and perceptions of happiness and sadness induced by music: Similarities, differences, and mixed emotions. Psychology of Aesthetics, Creativity, and the Arts, 4, 47-56.

Husain, G., Thompson, W., \& Schellenberg, E. (2002). Effects of musical tempo and mode on arousal, mood, and spatial abilities. Music Perception, 20, 151-171.

Hyde, K., Lerch, J., Norton, A., Forgeard, M., Winner, E., Evans, A., \& Schlaug, G. (2009). Musical training shapes structural brain development. The Journal of Neuroscience, 29, 3019-3025.

Jefferies, L., Smilek, D., Eich, E., \& Enns, J. (2008). Emotional valence and arousal interact in attentional control. Psychological Science, 19, 290-295. doi: 10.1111/j.14679280.2008.02082.x

Jiménez-Ortega, L., Martín-Loeches, M., Casado, P., Sel, A., Fondevila, S., Herreros de Tejada, P., Schacht, A., \& Sommer, W. (2012). How the emotional content of discourse affects language comprehension. PLoS ONE, 7: e33718.

Johansson, B.B. (2008). Language and music: What do they have in common and how do they differ? A neuroscientific approach. European Review, 16, 413-427. doi:10.1017/S1062798708000379

Juslin, P., \& Laukka, P. (2004). Expression, perception, and induction of musical emotions: A review and a questionnaire study of everyday listening. Journal of New Music Research, 33, 217-238.

Juslin, P., Liljeström, S.,Västfjäll, D., Barradas, G., \& Silva, A. (2008). An experience sampling study of emotional reactions to music: Listener, music, and situation. Emotion, 8, 668-683.

Juslin, P., \& Sloboda, J. (2010). Music and Emotion: Theory, Research, Applications. Oxford University Press: New York.

Juslin, P., \& Västfjäll, D. (2008). Emotional responses to music: The need to consider underlying mechanisms. Behavioral and Brain Sciences, 31, 559-621.

Koelsch, S. (2011). Towards a neural basis of processing musical semantics. Physics of Life Reviews, 8, 89-105. 
Koelsch, S., Gunter, T., Cramon, Y., Zysset, S., Lohmann, G., \& Friederici, A. (2002). Bach speaks: A cortical "language-network" serves the processing of music. NeuroImage, 17, 956-966.

Koelsch, S., Jentschke, S., Sammler, D., \& Mietchen, D. (2007). Untangling syntactic and sensory processing: An ERP study of music processing. Psychophysiology, 44, 476490. doi: 10.1111/j.1469-8986.2007.00517.x

Koelsch, S., Kasper, E., Sammler, D., Schulze, K., Gunter, T., \& Friederici, A. D. (2004). Music, language and meaning: Brain signatures of semantic processing. Nature Neuroscience, 7, 302-307.

Koelsch, S., Schröger, E., \& Tervaniemi, M. (1999). Superior pre-attentive auditory processing in musicians. NeuroReport, 10, 1309-1313.

Kreutz, G., Ott, U., Teichmann, D., Osawa, P., \& Vaitl, D. (2008). Using music to induce emotions: Influences of musical preference and absorption. Psychology of Music, 36, 101-126.

Laurier, C., Grivolla, J., \& Herrera, P. (2008). Multimodal music mood classification using audio and lyrics. In 2008 Seventh International Conference on Machine Learning and Applications.

Levenson, R. (2011). Basic emotion questions. Emotion Review, 3, 3-379. doi: $10.1177 / 1754073911410743$

Lewis,P., Critchley, H., Rotshtein, P., \& Dolan, R. (2006). Neural correlates of processing valence and arousal in affective words. Cerebral Cortex, 17, 742-748. doi:10.1093/cercor/bhk024

Lundqvist, L., Carlsson, F., Hilmersson, P., \& Juslin, P. N. (2009). Emotional responses to music: Experience, expression, physiology. Psychology of Music, 37, 61-90.

Maess, B., Koelsch, S., Gunter, T. C., \& Friederici, A. D. (2001). Musical syntax is processed in Broca's area: An MEG study. Nature Neuroscience, 4, 540-545.

Matovic, D., Koch, A., \& Forgas, J. (2014). Can negative mood improve language understanding? Affective influences on the ability to detect ambiguous communication. Journal of Experimental Social Psychology, 52, 44-49.

McConnell, M., \& Shore, D. (2011). Upbeat and happy: Arousal as an important factor in studying attention. Cognition \& Emotion, 25, 1184-1195. doi: $10.1080 / 02699931.2010 .524396$

Mihalcea, R., \& Strapparava, C. (2012). Lyrics, music and emotions. Proceedings of the 2012 Joint Conference on Empirical Methods in Natural Language Processing and Computational Natural Language Learning, pp. 590-599. Jeju Island: Korea.

Minagawa-Kawai, Y., Mori, K., \& Sato, Y. (2005). Different brain strategies underlie the categorical perception of foreign and native phonemes. Journal of Cognitive Neuroscience, 17, 1376-1385.

Mitchell, R., \& Phillips, L. (2007). The psychological, neurochemical and functional neuroanatomical mediators of the effects of positive and negative mood on executive functions. Neuropsychologia, 45, 617-629.

Mithen, S. (2009). The music instinct: The evolutionary basis of musicality. The Neurosciences and Music III - Disorders and Plasticity: Annals of the New York Academy of Science, 1169, 3-12.

Moreno, S., \& Bidelman, G. (2014). Examining neural plasticity and cognitive benefit through the unique lens of musical training. Hearing Research, 308, 84-97.

Moreno, E., Rodriguez-Fornells, A., \& Laine, M. (2008). Event-related potentials (ERPs) in the study of bilingual language processing. Journal of Neurolinguistics, 21, 477-508. 
Nishikawa, N., Itoyama, K., Fujihara, H., Goto, M., Ogata, T., \& Okuno, H. (2011). A musical mood trajectory estimation method using lyrics and acoustic features. In MIRUM'11, November 30, Scottsdale, Arizona, USA.

Oechslin, M., Van de Ville, D., Lazeyras, F., Hauert, C., \& James, C. (2013). Degree of musical expertise modulates higher order brain functioning. Cerebral Cortex, 23, 2213-2224. doi:10.1093/cercor/bhs206

Olafson, K., \& Ferraro, R. (2001). Effects of emotional state on lexical decision performance. Brain and Cognition, 45, 15-20.

Opitz, B., \& Degner, J. (2012). Emotionality in a second language: It's a matter of time. Neuropsychologia, 50, 1961-1967.

Patel, A.D. (2007). Language, music and the brain: A resource sharing framework. Keynote paper for "Language and Music as Cognitive Systems", May 11-13, 2007, Cambridge University, England.

Patel, A.D. (2008). Music, Language and the Brain. New York: Oxford University Press.

Patel, A.D., Gibson, E., Ratner, J., Besson, M., \& Holcomb, P. J. (1998). Processing syntactic relations in language and music: An event-related potential study. Journal of Cognitive Neuroscience, 10, 717-733.

Pereira, C., Teixeira, J., Figueiredo, P., Xavier, J., Castro, S., \& Brattico, E. (2011). Music and emotions in the brain: Familiarity matters. PLOS ONE, 6, e27241.

Peretz, I. (2006). The nature of music from a biological perspective. Cognition, 100, 1-32. doi:10.1016/j.cognition.2005.11.004

Peretz, I., \& Coltheart, M. (2003). Modularity of music processing. Nature Neuroscience, 6, 688-691.

Peretz, I., Radeau, M., \& Arguin, M. (2004). Two-way interactions between music and language: Evidence from priming recognition of tune and lyrics in familiar songs. Memory and Cognition, 32, 142-152.

Pillai, J., Araque, J., Allison, J., Sethuraman, S., Loring, D., Thiruvaiyaru, D., Ison, C., Balan, A., \& Lavin, T. (2003). Functional MRI study of semantic and phonological language processing in bilingual subjects: Preliminary findings. NeuroImage, 19, 565-576. doi:10.1016/S1053-8119(03)00151-4

Qualtrics Software, Version (55581) of the Qualtrics Research Suite. Copyright (C) 2014. Qualtrics, Provo, UT, USA. http://www.qualtrics.com.

Roberts, L., \& Felser, C. (2011). Plausibility and recovery from garden-paths in secondlanguage sentence processing. Applied Psycholinguistics, 32, 299-331.

Rodrigues, A.C., Loureiro, M.A., \& Caramelli, P. (2010). Musical training, neuroplasticity and cognition. Dementia e Neuropsychologia, 4, 277-286. Retrieved from www.demneuropsy.com.br/resumo.asp?id $=240$

Russell, J. (1980). A circumplex model of affect. Journal of Personality and Social Psychology, 39, 1161-1178.

Rüschemeyer, S., Fiebach, C., Kempe, V., \& Friederici, A. (2005). Processing lexicalsemantic and syntactic information in first and second language: FMRI evidence from German and Russian. Human Brain Mapping, 25, 266-286.

Sammler, D., Baird, A., Valabregue, R., Clement, S., Dupont, S., Belin, P., \& Samson, S. (2010). The relationship of lyrics and tunes in the processing of unfamiliar songs: A functional magnetic resonance adaptation study. The Journal of Neuroscience, 30, 3572-3578.

Sanders, L., \& Neville, H. (2003). An ERP study of continuous speech processing II. Segmentation, semantics, and syntax in non-native speakers. Cognitive Brain Research, 15, 214-227. 
Santiago-Rivera, A., \& Altarriba, J. (2002). The role of language in therapy with the SpanishEnglish bilingual client. Professional Psychology: Research and Practice, 33, 30-38. doi: $10.1037 / / 0735-7028.33 .1 .30$

Schellenberg, E. (2005). Music and cognitive abilities. Current Directions in Psychological Science, 14, 317-320. doi: 10.1111/j.0963-7214.2005.00389.x

Scherer, K. (2004). Which emotions can be induced by music? What are the underlying mechanisms? And how can we measure them? Journal of New Music Research, 33, 239-251. doi: 10.1080/0929821042000317822.

Schlaug, G., Jänke, L., Huang, X., Staiger, J., \& Steinmetz, H. (1995). Increased corpus callosum size in musicians. Neuropsychologia, 33, 1047-1055.

Schlaug, G., Norton, A., Overy, K., \& Winner, E. (2005). Effects of music training on the child's brain and cognitive development. Annals of the New York Academy of Sciences, 1060, 219-230. doi: 10.1196/annals.1360.015

Schmithorst, V., \& Wilke, M. (2002). Differences in white matter architecture between musicians and non-musicians: A diffusion tensor imaging study. Neuroscience Letters, 321, 57-60.

Schwarz, N. (2010). Feelings-as-information theory. In P.Van Lange, A. Kruglanski, \& E. T. Higgins (Eds.), Handbook of Theories of Social Psychology (pp. 289-308). Sage.

Schwarz, N., Bless, H., \& Bohner, G. (1991). Mood and persuasion: Affective states influence the processing of persuasive communications. Advances in Experimental Social Psychology, 24, 161-199.

Seung, Y., Kyong, J., Woo, S., Lee, B., \& Lee, K. (2005). Brain activation during music listening in individuals with or without prior music training. Neuroscience Research, 52, 323-329. doi:10.1016/j.neures.2005.04.011

Sousou, S. (1997). Effects of melody and lyrics on mood and memory. Perceptual and Motor Skills, 85, 31-40.

Storbeck, J., \& Clore, G. (2007). On the interdependence of cognition and emotion. Cognition \& Emotion, 21, 1212-1237. doi: 10.1080/02699930701438020

Storbeck, J., \& Clore, G. (2008). Affective arousal as information: How affective arousal influences judgments, learning, and memory. Social and Personality Psychology Compass, 2, 1824-1843. doi: 10.1111/j.1751-9004.2008.00138.x

Stratton, V., \& Zalanowski, A. (1994). Affective impact of music vs. lyrics. Empirical Studies of the Arts, 12, 173-184.

Tesoriero, M., Rickard, N. (2012). Music-enhanced recall: An effect of mood congruence, emotional arousal, or emotion function? Musicae Scientiae, 16, 340-356.

Vissers, C., Virgillito, D., Fitzgerald, D., Speckens, A., Tendolkar, I., Oostrom, I., \& Chwilla, D. (2010). The influence of mood on the processing of syntactic anomalies: Evidence from P600. Neuropsychologia, 48, 3521-3531.

Vuoskoski, J., \& Eerola, T. (2012). Can sad music really make you sad? Indirect measures of affective states induced by music and autobiographical memories. Psychology of Aesthetics, Creativity, and the Arts, 6, 204-213.

Watson, D.,Clark, L. A., \& Tellegen, A. (1988). Development and validation of brief measures of positive and negative affect: The PANAS scales. Journal of Personality and Social Psychology, 54, 1063-1070.

Wolpert, R. (2000). Attention to key in a nondirected music listening task: Musicians vs. nonmusicians. Music Perception: An Interdisciplinary Journal, 18, 225-230.

Zajonc, R. (1980). Feeling and thinking: Preferences need no inferences. American Psychologist, 35, 151-175. 
Zajonc, R. (2000). Feeling and thinking: Closing the debate over the independence of affect. In J. P. Forgas (Ed.), Feeling and thinking: The role of affect in social cognition. Studies in emotion and social interaction (Vol. 2., pp. 31-58). New York: Cambridge University Press

Zentner, M., Grandjean, D., \& Scherer, K. R. (2008). Emotions evoked by the sound of music: Characterization, Classification, and measurement. Emotion, 8, 494-521. 
APPENDIX A

\begin{tabular}{|c|c|c|c|c|}
\hline Name & Key & Words & BPM & Error? \\
\hline POSITIVE 1 & $\mathrm{D}$ & 61 & 132 & $\mathrm{Y}$ \\
\hline POSITIVE 2 & $\mathrm{E}$ & 60 & 138 & $\mathrm{Y}$ \\
\hline POSITIVE 3 & $\mathrm{G}$ & 60 & 144 & $\mathrm{~N}$ \\
\hline POSITIVE 4 & $\mathrm{~B}$ & 49 & 152 & $\mathrm{Y}$ \\
\hline POSITIVE 5 & $\mathrm{D}$ & 56 & 144 & $\mathrm{Y}$ \\
\hline POSITIVE 6 & $\mathrm{C}$ & 59 & 144 & $\mathrm{~N}$ \\
\hline POSITIVE 7 & $\mathrm{G}$ & 54 & 132 & $\mathrm{~N}$ \\
\hline POSITIVE 8 & $\mathrm{D}$ & 58 & 138 & $\mathrm{Y}$ \\
\hline POSITIVE 9 & $\mathrm{~F}$ & 60 & 144 & $\mathrm{Y}$ \\
\hline POSITIVE 10 & A & 62 & 138 & $\mathrm{~N}$ \\
\hline POSITIVE 11 & A & 47 & 144 & $\mathrm{~N}$ \\
\hline POSITIVE 12 & B & 55 & 138 & $\mathrm{~N}$ \\
\hline POSITIVE 13 & $\mathrm{E}$ & 55 & 160 & $\mathrm{Y}$ \\
\hline POSITIVE 14 & $\mathrm{~F}$ & 48 & 152 & $\mathrm{Y}$ \\
\hline POSITIVE 15 & A & 46 & 120 & $\mathrm{~N}$ \\
\hline POSITIVE 16 & $\mathrm{C}$ & 43 & 138 & $\mathrm{~N}$ \\
\hline POSITIVE 17 & G & 56 & 152 & $\mathrm{Y}$ \\
\hline POSITIVE 18 & $\mathrm{E}$ & 55 & 152 & $\mathrm{~N}$ \\
\hline POSITIVE 19 & $\mathrm{C}$ & 57 & 132 & $\mathrm{Y}$ \\
\hline POSITIVE 20 & $\mathrm{~F}$ & 62 & 132 & $\mathrm{~N}$ \\
\hline AVG & & 55.15 & 141.3 & \\
\hline NEGATIVE 1 & Dm & 56 & 76 & $\mathrm{~N}$ \\
\hline NEGATIVE 2 & Em & 59 & 84 & $\mathrm{~N}$ \\
\hline NEGATIVE 3 & $\mathrm{Bm}$ & 56 & 84 & $\mathrm{Y}$ \\
\hline NEGATIVE 4 & $\mathrm{CHm}$ & 58 & 84 & $\mathrm{~N}$ \\
\hline NEGATIVE 5 & $\mathrm{~F} \# \mathrm{~m}$ & 47 & 84 & $\mathrm{~N}$ \\
\hline NEGATIVE 6 & $\mathrm{Dm}$ & 47 & 80 & $\mathrm{Y}$ \\
\hline NEGATIVE 7 & $\mathrm{C} \# \mathrm{~m}$ & 45 & 76 & $\mathrm{~N}$ \\
\hline NEGATIVE 8 & $\mathrm{Dm}$ & 61 & 72 & $\mathrm{~N}$ \\
\hline NEGATIVE 9 & $\mathrm{Am}$ & 62 & 84 & $\mathrm{Y}$ \\
\hline NEGATIVE 10 & $\mathrm{Gm}$ & 55 & 84 & $\mathrm{~N}$ \\
\hline NEGATIVE 11 & $\mathrm{Fm}$ & 62 & 88 & $\mathrm{Y}$ \\
\hline NEGATIVE 12 & $\mathrm{Cm}$ & 64 & 80 & $\mathrm{Y}$ \\
\hline NEGATIVE 13 & Em & 60 & 80 & $\mathrm{~N}$ \\
\hline NEGATIVE 14 & $\mathrm{Bm}$ & 54 & 84 & $\mathrm{Y}$ \\
\hline NEGATIVE 15 & $\mathrm{Am}$ & 46 & 88 & $\mathrm{Y}$ \\
\hline NEGATIVE 16 & $\mathrm{Gm}$ & 55 & 88 & $\mathrm{Y}$ \\
\hline NEGATIVE 17 & $\mathrm{Cm}$ & 55 & 88 & $\mathrm{~N}$ \\
\hline NEGATIVE 18 & $\mathrm{Fm}$ & 51 & 80 & $\mathrm{Y}$ \\
\hline NEGATIVE 19 & $\mathrm{~F} \# \mathrm{~m}$ & 55 & 69 & $\mathrm{Y}$ \\
\hline NEGATIVE 20 & $\mathrm{Am}$ & 56 & 86 & $\mathrm{~N}$ \\
\hline AVG & & 55.25 & 81.95 & \\
\hline
\end{tabular}




\section{APPENDIX B}

Positive and Negative Lyrics and Chords. Words in Italics have been replaced by error words in bold.

\section{POSITIVE 1 - 61 words, 132bpm}

Intro: D, A, E

D A E

Now that I've found you, troubles just fade away,

D A E

You're constantly in my mind, and that's how I want it to stay

F\#m

I love you more than anything, that I've ever dreamed of,

$\mathrm{D}$

We could go travelling and meet so many people,

A $\quad$ E

You, ... and me

D A E

Time means nothing, when WRAP we're together

D A E D........... A, ... E.

Everything just turns out fine, let's stay like this, .... forever.

POSITIVE 2 - 60 words, $138 \mathrm{bpm}$

Intro - E, B, F\#, B, F\#

E B F\# B, F\#, E B F\#, B, F\#,

No matter how hard it seems, it's gonna be ok,

E B F\# B F\# E B $\quad$ F\# B F\#

I can promise you that, oooh, I can promise you that

E B F\# B, F\#, E B F\#, B, F\#,

There are people, everywhere, that can lift you up,

E B F\# B F\# E B F B F\#

I can promise you that, oooooh, I can promise you that,

F\# E B

You'll be fine all of the time TRAIN, when you've got your friends around you

F\# E B

Anytime you need, they'll come you see

POSITIVE 3 - 60 words, 144bpm

Intro - G, D, C, D

G D $\quad$ C $\quad$ D

I'm gonna write you a letter,

G D C D

Draw you a picture too

G D C C D

I want you to remember,

$\begin{array}{lllllll}\text { G } & \text { D } & \text { C } & \text { D } & \text { G } & \text { D } & \text { C }\end{array}$

This day we had, me and you, me and you 
G D C C D

We picked flowers and we ran around

G D $\quad$ C D

We threw them in the air then fell to the ground

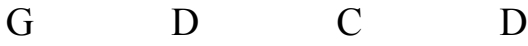

Today's a day I will never forget

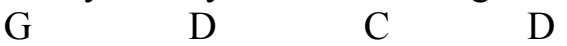

This day when we first met

$\mathrm{G}$

Me and you,

POSITIVE 4 - 49 words, 152 bpm

Intro - B, A, E

B A E

Oooh I'm loving life right now,

B A E

Everything is going great

B A E

I look out my window,

B A E

And see the birds there on the lake

F\# E

Summertime, everytime, it makes me smile,

B A E

It's like nothing else

B A E

I'm lying on the soft green GROSS ground

B A E

All i hear are peaceful sounds

B

It's like nothing else

POSITIVE 5 - 56 words, 144bpm

Intro - D C G

$\begin{array}{llllllllllll}D & \text { C } & \text { G } & \text { D } & \text { C } & \text { G }\end{array}$

I'm standing at the airport, waiting for you

$\begin{array}{llllll}D & C & G & \text { D } & \text { C } & \text { G }\end{array}$

The other loved LYNCH ones stand here too

D C G

From behind, someone starts singing,

D C G

Up ahead, people start dancing,

$\begin{array}{lllll}D & \mathrm{C} & \mathrm{G} & \mathrm{D} & \mathrm{CG}\end{array}$

All around, music's being made

$\begin{array}{lll}\text { D } & \text { C }\end{array}$ 
A little bit of drums, to start the beat,

D C G

People dancing, moving their feet

D C G

Trumpet from the corner, now it's complete,

D $\quad \mathrm{C}$ G $\quad$ D

Everyone moving, moving their feet

POSITIVE 6 - 59 words, $144 \mathrm{bpm}-1$

Intro - C F G C

$\mathrm{C} \quad \mathrm{F}$

I'm living in a happy world,

G C

A place where everyone's safe

$\mathrm{F}$

I'm dreaming we all live together,

$\mathrm{G}$

and freedom is the way,

C $\quad \mathrm{F} \quad \mathrm{G}$

I'm dreaming of smiling faces

F G

If you believe it'll happen to you,

Em $F$

dream all your dreams and they'll come true

C F G

I'm dreaming of a new world soon,

A place where everyone's safe,

$\begin{array}{lll}F & G & C\end{array}$

I'm dreaming it'll happen soon

POSITIVE 7 - 54 words, 132 bpm

Intro - G C D

G C D

Walking down the path, I see your face,

G C D

It's so nice, we're in the same place

G C D

You smile at me, I blush and smile at you

G $\quad$ C $\quad$ D

As you get closer, I see in your eyes,

G C D

Sparkling and, sunshine,

G $\quad$ C $\quad$ D

It's times like these that, i wanna smile at you 
G D C G D C

Oooh, now you're here

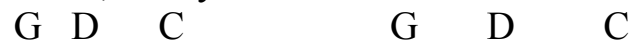

Oooh, everything is clear

POSITIVE 8 - 58 words, 138bpm

Intro - D G A

D G A

When everything is going well you know it,

D

G A

Feel it in your bones, feel it in your toes, own it

E A D

Nothing else can get, in the waaaay

E A D

Nothing else can get, in the waaaay

D

Love the friends you're with,

G A

Love the place PIG you're in, be happy

$\mathrm{D}$

G A D

See it with your eyes, love never dies, it stays, with you

POSITIVE 9 - 60 words, 144bpm

Intro - F Bb C

$\begin{array}{llllll}\mathrm{F} & \mathrm{Bb} & \mathrm{C} & \mathrm{F} & \mathrm{Bb} & \mathrm{C}\end{array}$

Little girl was sitting in the park after school,

$\mathrm{F} \quad \mathrm{Bb} \quad \mathrm{C} \quad \mathrm{F} \quad \mathrm{Bb} \mathrm{C}$

She got thinking... what is happiness?

$\begin{array}{llllll}\mathrm{F} & \mathrm{Bb} & \mathrm{C} & \mathrm{F} & \mathrm{Bb} & \mathrm{C}\end{array}$

She thought I'm happy with my friends and family

$\begin{array}{llllll}\mathrm{F} & \mathrm{Bb} & \mathrm{C} & \mathrm{F} & \mathrm{Bb} & \mathrm{C}\end{array}$

I'm also happy HAIRY when my friends play games with me

$\mathrm{F}$

Cause happiness is sun,

$\mathrm{Bb}$

Happiness when you run,

C $\mathrm{F}$

Happiness... can be anything

$\mathrm{F}$

Happiness is cake and tea,

$\mathrm{Bb}$

Happiness sounds good to me,

C

Happiness... can be anything 
POSITIVE 10 - 62 words, $138 \mathrm{bpm}$

Intro - A E D E

A E D E

He was the boy next door

A E D E

They grew up as friends

A E D E

Suddenly he wanted more,

A E D E

She became his girlfriend

A E D E

They married in the spring one year,

A $\quad$ E $\quad D \quad$ E

He leaned over, whispered in her ear

$\begin{array}{llllllll}\text { A } & \text { E } & \text { D } & \text { E } & \text { A } & \text { E } & \text { D } & \text { E }\end{array}$

You're my best friend in the whole world
A E
D E
A E D E

I've never loved anyone but you

A E D E A E D E

She leaned over, looked him in the eye

A E D E A E D E

And she said, i love you too

POSITIVE 11- 47 words, 144bpm

Intro - A, D, A, D

A D

When you're near me,

A

Time slows down

D

I'm so happy

E

When you're around

One look, from you

$\begin{array}{llll}\text { A } & \text { D } & \text { A } & \text { D }\end{array}$

You make my day, everyday, you make my day, everyday

D

I like it when you smile in the morning

A D

I like it when you look confused

A

You make my day

POSITIVE 12 - 55 words, 138bpm 
Intro - B, E, B, F\#

$\mathrm{B}$

$\mathrm{E}$

The time, is now

$\mathrm{B} \quad \mathrm{F} \#$

To find, your dream

B E

You think it's hard,
B
F\#

B E

B F\#

But it's easier than it seeeems

B E

Because you, have it inside,

B F\#

potential is everywhere

B E

Because life's what you make it,

B F\#

And you know what to do

F\# E

Work hard, be happy,

B F\#

Relax when you need,

F\# E

Work hard, be happy, your heart will be freed

POSITIVE 13 - 55 words, $160 \mathrm{bpm}$

Intro - E, A, E E

E

The time has come again

The sun has come to play

A

We can have a picnic

Stay outside all day

E

Eat watermelon

$\mathrm{B}$

Lie on the grass

\section{A}

All those happy HERBAL faces

$\mathrm{E}$

This is where I'm meant to be

At last

B A E

Ooooh

E

Birds are flying high 
B

Cold has gone away

A E

I can go out any time of day

POSITIVE 14 - 48 words, 152 bpm

Intro - F, Dm, Bb, C

$\mathrm{F} \quad \mathrm{Dm} \quad \mathrm{Bb} \quad \mathrm{C}$

I just found out, all my troubles will go away

F Dm $\quad \mathrm{Bb} \quad \mathrm{C}$

I just found out, good times are here to stay

F $\mathrm{Dm} \quad \mathrm{Bb} \mathrm{C}$

Ooooooooh

F $\quad$ Dm $\quad B b \quad C$

This is the best day, of my life

F $\quad \mathrm{Dm} \quad \mathrm{Bb} \quad \mathrm{C} \quad \mathrm{FFF}$

No more bad days DOUGH, it's kinda nice

F $\quad \mathrm{Dm} \quad \mathrm{Bb} \quad \mathrm{C}$

I'm exactly where I want to be

$\mathrm{F} \quad \mathrm{Dm} \quad \mathrm{Bb} \quad \mathrm{C}$

Everything is going well for me

POSITIVE 15 - 46 words, 120 bpm

Intro-Asus2, A, Asus2, A, D, Asus2, A, Asus2 etc

Asus 2

A

Driving to the sun

Asus 2 A

Wherever it may be

$\mathrm{D}$

Time to travel

Asus2 A

To the sea

Asus 2 A

Driving down the road

Asus $2 \quad$ A

Wherever it may lead

D

Music playing

Asus2 A

I feel free

E

D

The time is now to change my life

Asus2 A

For the better 
The time is now I'm gonna drive Asus2 A

Forever

POSITIVE 16 - 43 words, 138bpm

Intro- $\mathrm{C}, \mathrm{G} \quad \mathrm{F}$

C $\quad \mathrm{G} \quad \mathrm{F}$

Let's pretend, we are kids

C G F

Let's pretend we have no worries

C G G

Let's pretend this is it

$\begin{array}{llllll}\text { C } & \text { G } & \text { F } & \text { C G F }\end{array}$

And live, live, let's just live

C G F

Let's appreciate everything

C G F

Especially little things

$\begin{array}{lllllll}C & G & F & C & G & \text { F }\end{array}$

Let's walk hand in hand and live, live, let's just live

G F C

Can everybody just live...

POSITIVE 17 - 56 words, 152 bpm

Intro - G C D F, G C D F F F

$\mathrm{G} \quad \mathrm{C}$

When I moved here

D F

I knew everything would be ok

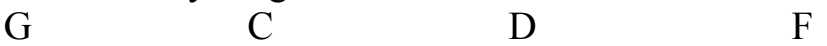

Everyone I've met seems to know me and remembers my name

G C D

This place is nice

G C D $\quad$ F

People are warm, beer is cold, time to stay in one place

F

Stay in one place

G C D

I like LOCK this town it's now my home

G C D

I like this place, it's my own

POSITIVE 18 - 55 words, 152 bpm

Intro - E, F\#, B,

E $F \#$ B E 
Riding my bike by the sea

F\# B E

A seagull comes and looks at me

F\# B E

I see it in his eyes

He wants to know if I'm free

$$
\text { F\# B } \quad \text { E } \quad \text { F\# } \text { B }
$$

F\# E B

Well seagull that depends on your definition

F\# B E

I'd certainly like to think I am

$\mathrm{E}$

I'm free

E F\# B E

$\mathrm{I}$ ride further along

F\# B E F\# B

Start to sing my new song

B

I am free

POSITIVE 19 - 57 words, 132bpm

Intro - C F G

C $\quad$ F $\quad$ G

When I'm with you everything feels ok

C F G

When I'm with you, my fears FLAMES go away

C $\quad \mathrm{F} \quad \mathrm{G}$

Because I know, you are mine

$\mathrm{C} \quad \mathrm{F} \quad \mathrm{G}$

Yes I know, you are mine

C $\quad$ F $\quad$ G

Times like these, I know you're the one for me

C F G

In your arms, there's no place I'd rather be

C F G

Because I know, you are mine

C $\quad \mathrm{F} \quad \mathrm{G}$

I know, you are mine

POSITIVE 20 - 62 words, 132 bpm

Intro $-\mathrm{F}, \mathrm{Bb}, \mathrm{C}$

$\mathrm{F} \quad \mathrm{Bb} \quad \mathrm{C}$

Everyone needs a friend like you

$\begin{array}{llllllllllllll}\mathrm{F} & \mathrm{Bb} & \mathrm{C} & \mathrm{F} & \mathrm{Bb} & \mathrm{C}\end{array}$

We have adventures and talk everything through 


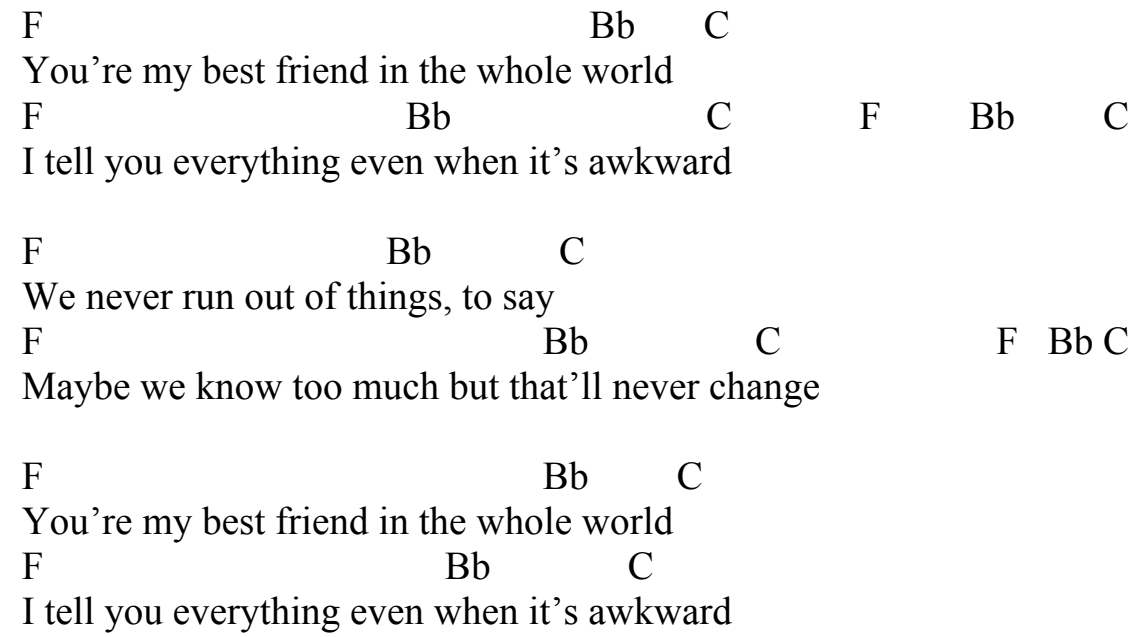

\section{NEGATIVE 1 - 56 words, $76 \mathrm{bpm}$}

Intro - Dm, Am,

Dm Am

Alone, lonely and sad

Dm Am

My friends were all that I had

$$
\mathrm{F} \quad \mathrm{Am}
$$

But it's hard to hold on,

Dm

When I can't see,

F Am Dm

Why anyone could possibly love me

Dm Am

Once, I was ok,

Dm Am

Then you came, and you took it away

$\mathrm{F} \quad \mathrm{Am}$

Now when I see you,

Dm

I breakdown and cry

F Am Dm

I can't handle, that look in your eye

NEGATIVE 2 - 59 words, 84bpm

Intro - Em, D, Em D

I have, so much news, that I, I want to share,

Em

D

Things I would have said, if you were still here,

Em D

But you're... gone, now, 
Em D

You will, never be back, now

Em D

I'm all alone, with no one to phone

Em D

I sleep in this bed, every night on my own,

$$
\text { Em D }
$$

Cause you're, gone, now,

Em $\quad D \quad$ Em

You will, never be back, now

NEGATIVE 3 - 56 words, 84bpm

Intro - Bm, F\#m

$\mathrm{Bm} \quad \mathrm{F} \# \mathrm{~m}$

This was the first time

$\mathrm{Bm} \quad \mathrm{F} \# \mathrm{~m}$

I'd lost someone, so dear

Bm F\#m

This was the first time,

$\mathrm{Bm} \quad \mathrm{F} \# \mathrm{~m}$

Now grief becomes clear
D
$\mathrm{Bm}$
$\mathrm{F} \# \mathrm{~m}$

The sad song plays, as they carry you away

D Bm F\#m

To another place, I don't know the name

Bm $\quad \mathrm{F} \# \mathrm{~m} \quad \mathrm{Bm} \quad \mathrm{F} \# \mathrm{~m}$

Family watch WIPE on, I can't believe you're actually gone

Bm $\mathrm{F} \# \mathrm{~m}$

Cause, this was the first time,

$\mathrm{Bm} \quad \mathrm{F} \# \mathrm{~m}$

This was the first time...

NEGATIVE 4 - 58 words, 84bpm

Intro $-\mathrm{CHm}, \mathrm{F} \# \mathrm{~m}$

$\mathrm{C} \# \mathrm{~m} \quad \mathrm{~F} \# \mathrm{~m}$

She's falling apart, and nobody notices,

$\mathrm{CHm} \quad \mathrm{F} \# \mathrm{~m} \quad \mathrm{Bm}$

Faking a smile, hiding the hopelessness,

$$
\text { E Bm }
$$

She's too young, to be this sad

$$
\mathrm{E} \quad \mathrm{CHm}
$$

She's too young, to be this sad

$\mathrm{C} \# \mathrm{~m} \quad \mathrm{~F} \# \mathrm{~m}$

She's crying alone, in bed, late at night,

$\mathrm{CHm} \quad \mathrm{F} \# \mathrm{~m} \quad \mathrm{Bm}$ 
Nobody knows that she wants to give up the fight

She's too young, to be this sad,

$$
\text { E F\#m }
$$

She's too young, to be this sad

\section{NEGATIVE 5 - 47 words, 84 bpm}

Intro $-\mathrm{F} \# \mathrm{~m}, \mathrm{Bm}$,

$\mathrm{F} \# \mathrm{~m}$

There's a certain kind of sadness,

$\mathrm{Bm}$ $\mathrm{F} \# \mathrm{~m}$

And it comes, to people on their own

$\mathrm{Bm} \quad \mathrm{F} \# \mathrm{~m}$

It comes, unwanted, but once alone, you're alone

$\mathrm{CHm} \quad \mathrm{Bm}$

You can stay up all night,

$\mathrm{CHm} \quad \mathrm{Bm} \quad \mathrm{CHm}$

You can wonder why things never go right,

$\mathrm{Bm}$

Is it because of you?

$\mathrm{C} \# \mathrm{~m} \quad \mathrm{Bm} \quad \mathrm{F} \# \mathrm{~m}$

Because you ruin, everything you do

NEGATIVE 6 - 47 words, 80 bpm

Intro - Dm, Am

Dm Am

Sometimes it feels like I'm drowning,

Dm Am

You always hurt me so bad,

C $\quad$ Em Am $\quad$ Em

Every day and night, you hit me and we fight

Dm Am

Sometimes it feels like I'm falling down,

Dm

Am

Away ANKLE from the light,

$\mathrm{C}$

Em

Maybe I should just give up everything, Em Am

Maybe I should slip into the night

NEGATIVE 7 - 45 words, 76 bpm

Intro $-\mathrm{CHm}, \mathrm{F} \# \mathrm{~m}$

$\mathrm{C} \# \mathrm{~m} \quad \mathrm{~F} \# \mathrm{~m}$

You don't understand

C\#m F\#m

Just why I'm crying 
$\mathrm{C} \# \mathrm{~m} \quad \mathrm{~F} \# \mathrm{~m}$

You want me to hold your hand

$\mathrm{CHm} \quad \mathrm{F} \# \mathrm{~m}$

But inside I'm dying

$\mathrm{CHm} \quad \mathrm{F} \# \mathrm{~m}$

Cause you left me, you left me all alone

$\mathrm{C} \# \mathrm{~m} \quad \mathrm{G} \# \mathrm{~m}$

Just when I needed you the most

$\mathrm{CHm} \quad \mathrm{F} \# \mathrm{~m}$

I lost everything I own,

$\mathrm{C} \# \mathrm{~m} \quad \mathrm{G} \# \mathrm{~m} \quad \mathrm{C} \# \mathrm{~m}$

And then you, you left me

NEGATIVE 8 - 61 words, $72 \mathrm{bpm}$

Intro - Dm Am Em Am

Dm Am Em Am

It's raining all day, it's raining all night too

Dm Am Em Am

There's nothing but grey, my outside view

Dm Am Em Am

I sit in the cold, I wish I had somebody, but,

Dm Am

no one loves me back,

Em Am

I think I hurt everybody

Dm Am Em Am

I try to sleep, but if I close my eyes, then I get nightmares

Dm Am Em Am Dm

Insomnia, it makes me weak, I might just hide here

NEGATIVE 9 - 62, 84bpm

Intro - Am Em Dm Em

Am Em

It's so sad, the state that we're in,

Dm

Em

The poor PINCH get poorer and the richer get richer

Am Em

Some are living off a dollar a day

Dm Em

While other's laugh, and they say that's ok

Am Em

So many people, with no place to live,

Dm Em

Others able but unwilling to give

Am Em

This is not the way, it should be 
Dm Em Am

When most of the world is unhappy

NEGATIVE 10 - 55 words, 84bpm

Intro - Gm, Cm

$\mathrm{Gm} \quad \mathrm{Cm} \quad \mathrm{Gm}$

I didn't know, that was the last time I'd see you

$\mathrm{Cm} \quad \mathrm{Gm}$

I didn't know, that soon you would be gone

$\mathrm{Cm}$

$\mathrm{Gm}$

I can't imagine how it would feel, to have all the breath, leave your body

$\mathrm{Gm} \quad \mathrm{Cm} \quad \mathrm{Gm}$

What a waste of life, you were only twenty five

$\mathrm{Cm}$

Gm

I wish and I wish, that you were still alive

NEGATIVE 11 - 62 words, 88 bpm

Intro - Fm Bm

Fm

I don't know why you went away,

$\mathrm{Bm}$

I want you back BELT in my life, I want you to stay but

$\mathrm{Cm}$ Bm Fm

I know, that you're gone

Fm

I miss the way that you touch, I miss the way you kiss,

$\mathrm{Bm}$

Why did you leave me, I must be so shit,

$\mathrm{Cm} \quad \mathrm{Bm} \quad \mathrm{Fm}$

I miss you

$\mathrm{Cm} \quad \mathrm{Bm}$

Don't you think for one second

Fm

That I don't miss you

NEGATIVE 12 - 64 words, 80bpm

Intro - Cm, Gm, Cm, Gm

$\mathrm{Cm}$

Hiding in the darkness,

$\mathrm{Gm}$

There's a secret lying there

$\mathrm{Cm}$

Secret of my sadness,

$\mathrm{Gm}$

I can't let it out to share 
$\mathrm{Cm}$

It could hurt somebody,

$\mathrm{Gm}$

I know it's dangerous,

$\mathrm{Cm}$

Full of melancholy,

$\mathrm{Gm}$

And thorns TENTS that hurt the rest of us

$\mathrm{Cm} \quad \mathrm{Gm}$

I can't keep it hiding anymore

$\mathrm{Cm} \quad \mathrm{Gm}$

Sadness swallows me up

Fm Gm

I'm pulled to the depths of despair,

Fm Gm Cm

Where I'm going there's no one else there

NEGATIVE 13 - 60 words, 80bpm

Intro - Em, Am

Em

You cheated on me, I just found out

Am

That you went and broke my heart

Em

With some other girl, that I don't know

Am

It won't be better tomorrow

Em

I don't want to hear, how you're in love

Am

That you never wanted to hurt me

Em

Am

Thought you were the one, the only one for me, Em

but now, we will never be

NEGATIVE 14 - 84bpm, 54 words

Intro - Bm, F\#m

$\mathrm{Bm} \quad \mathrm{F} \# \mathrm{~m}$

Let me tell you my story

$\mathrm{Bm} \quad \mathrm{F} \# \mathrm{~m} \quad \mathrm{Bm}$

They took me when I was a child

$\mathrm{F} \# \mathrm{~m}$

To a place full of heartache

$\begin{array}{llll}\mathrm{Bm} & \mathrm{F} \# \mathrm{~m} & \mathrm{Bm} & \mathrm{Bm}\end{array}$

When they hit me they hit hard 
$\mathrm{Bm} \quad \mathrm{F} \# \mathrm{~m}$

I don't remember my parents at all

$\mathrm{Bm} \quad \mathrm{F} \# \mathrm{~m}$

Or the town that I grew up in

$\mathrm{Bm} \quad \mathrm{F} \# \mathrm{~m}$

I only know what my number was

$\mathrm{Bm} \quad \mathrm{F} \# \mathrm{~m} \quad \mathrm{Bm}$

And that smiling SHIPWRECK is forbidden

NEGATIVE 15 - 46 words, 88bpm

Intro - Am, Em,

Am

I'm feeling shit today

Em

Why can't we all just get along?

Am

Cause this is not NECK how it's meant to be,

Em

I'm feeling sad, alone and lonely,

Dm Em

But every day, this is just how I feel

Dm

Em

The sadness here, every day is real

Am

I'm feeling shit today

NEGATIVE 16 - 55 words, 88 bpm

Intro - $\mathrm{Gm}, \mathrm{Cm}$,

$\mathrm{Gm}$

$\mathrm{Cm}$

She was all he had,

$\mathrm{Gm} \quad \mathrm{Cm}$

she was all that he had

Dm Cm Gm

Why can the world be so cruel, he said

$\mathrm{Gm} \quad \mathrm{Cm}$

When yesterday she was fine,

Gm $\quad \mathrm{Cm} \quad \mathrm{Dm}$

When yesterday, she was ok, $\mathrm{Cm} \quad \mathrm{Gm}$

They were planning POWDER a holiday

$\mathrm{Gm} \quad \mathrm{Cm}$

But now she's gone, she can't come back, 
$\mathrm{Gm} \quad \mathrm{Cm} \quad \mathrm{Gm}$

She's gone to a place where there's no coming back she's gone

NEGATIVE 17 - 55 words, 88bpm

Intro $-\mathrm{Cm}, \mathrm{Gm}$,

$\mathrm{Cm}$

I drank too much last night,

$\mathrm{Gm}$

I don't know who I am anymore

$\mathrm{Cm}$

I think that I got in a fight or two

Gm

But what happened, I'm not really sure

$\mathrm{Cm}$

I think I killed a man

Gm $\quad \mathrm{Cm}$

I don't know how it happened

But I found blood on my hands

$\mathrm{Gm} \quad \mathrm{Cm}$

How could I let this happen?

NEGATIVE 18 - 51 words, 80bpm.

Intro - Fm, Cm, Bbm

$\mathrm{Fm} \quad \mathrm{Cm}$

I lost my job

Bbm Fm

The same day as I lost LEECH you

Fm $\quad \mathrm{Cm} \quad$ Bbm $\quad$ Fm

I don't know which is worse, cause now I've got nothing to do

$\mathrm{Fm} \quad \mathrm{Cm} \quad \mathrm{Bbm} \quad \mathrm{Fm}$

I sit in my home all alone, all day, watching very bad tv

Fm $\quad \mathrm{Cm} \quad \mathrm{Bbm} \quad \mathrm{Fm}$

I've got no one to call, I've got nowhere to be, it's just me

NEGATIVE 19 - 55 words, 69 bpm

Intro - F\#m, C\#m, Bm, F\#m

$\mathrm{F} \# \mathrm{~m} \quad \mathrm{C} \# \mathrm{~m} \quad \mathrm{Bm} \quad \mathrm{F} \# \mathrm{~m}$

The hardest time, is when I close my eyes

$\mathrm{F} \# \mathrm{~m} \quad \mathrm{CHm} \quad \mathrm{Bm} \quad \mathrm{F} \# \mathrm{~m}$

When it's dark outside, I know I have to survive

$\mathrm{F} \# \mathrm{~m} \quad \mathrm{C} \# \mathrm{~m} \quad \mathrm{Bm} \quad \mathrm{F} \# \mathrm{~m}$

Just one more night, it should get better

$\mathrm{F} \# \mathrm{~m} \quad \mathrm{C} \# \mathrm{~m} \quad \mathrm{Bm} \quad \mathrm{F} \# \mathrm{~m}$

If I can get through just one more night

$\mathrm{F} \# \mathrm{~m} \quad \mathrm{C} \# \mathrm{~m} \quad \mathrm{Bm} \quad \mathrm{F} \# \mathrm{~m}$

But time slows down, the coldness CABBAGE covers me up 
F\#m C\#m Bm $\quad$ F\#m

The darkness stays with me, It won't give me up

NEGATIVE 20 - 56 words, 84bpm

Intro - Am, Em, Dm

Am Em Dm

You told me not to tell

Am

So I kept it all inside

Em

All those bad things you did to me

Dm

Too hard to believe

Am Em Dm Am

I kept it inside for so long that now it's killing me, it's eating me up

Am Em Dm Am

When did I end up like this, I'm a shell of myself, where did I go? 


\section{APPENDIX C}

\section{PILOT STUDY}

Hello! Thank you for agreeing to do my pilot study (:) You are wonderful!

I would like you to listen to 40 , one-minute songs, half of which will be positive sounding, and half of which will be negative sounding. Some of the lyrics of the songs will have errors in them - words that do not fit into the context of the song. At the end of each song, I will ask 1 ) if there was an error, and 2) if there was an error, what was the error word?

Please try and get as emotionally involved in the songs as possible. You will be asked to listen to all the positive songs together and all the negative songs together.

Firstly, I would like you to complete a quick mood scale: Indicate to what extent you feel this way right now, that is, at the present moment.

\begin{tabular}{|c|c|c|c|c|}
\hline $\begin{array}{l}1 \\
\text { Very Slightly or Not } \\
\text { at All }\end{array}$ & $\begin{array}{c}2 \\
\text { A Little }\end{array}$ & $\begin{array}{c}3 \\
\text { Moderately }\end{array}$ & $\begin{array}{c}4 \\
\text { Quite a Bit }\end{array}$ & $\begin{array}{c}5 \\
\text { Extremely }\end{array}$ \\
\hline \multicolumn{2}{|c|}{ 1. Interested } & & \multicolumn{2}{|c|}{ 11. Irritable } \\
\hline \multicolumn{2}{|c|}{ 2. Distressed } & & \multicolumn{2}{|c|}{ 12. Alert } \\
\hline \multicolumn{2}{|c|}{ 3. Excited } & & \multicolumn{2}{|c|}{ 13. Ashamed } \\
\hline \multicolumn{2}{|c|}{ 4. Upset } & & \multicolumn{2}{|c|}{ 14. Inspired } \\
\hline \multicolumn{2}{|c|}{ 5. Strong } & & \multicolumn{2}{|c|}{ 15. Nervous } \\
\hline \multicolumn{2}{|c|}{ 6. Guilty } & & \multicolumn{2}{|c|}{ 16. Determined } \\
\hline \multicolumn{2}{|c|}{ 7. Scared } & & \multicolumn{2}{|c|}{ 17. Attentive } \\
\hline \multicolumn{2}{|c|}{ 8. Hostile } & & \multicolumn{2}{|c|}{ 18. Jittery } \\
\hline \multicolumn{2}{|c|}{ 9. Enthusiastic } & & \multicolumn{2}{|c|}{ 19. Active } \\
\hline \multicolumn{2}{|c|}{ 10. Proud } & & \multicolumn{2}{|c|}{ 20. Afraid } \\
\hline
\end{tabular}

I have sent you the mp3's of all the songs, which are rated $\mathrm{P}$ (number), and N(number). On the next page I have randomised which order I would like you to listen to them. Please only listen to each song ONCE. Even if you're not sure if there's an error, please guess. I will also ask you how positive/negative you think the song sounds - please rate it on a scale of 15. Please be totally honest, as I can still change the songs at this stage to make them better! If you would like to say anything about the songs (improvements/don't like something/don't understand something etc.), please write that under the song. Please don't look at other stimuli during this time (e.g. internet), as this might affect your mood.

Thank you again!

Please listen to the songs with headphones.

Are you listening with headphones? Please indicate - YES NO

Note: The songs have not been professionally recorded yet, so they have a lower volume than most songs. Please adjust volume accordingly so you can hear the lyrics clearly. 


\section{APPENDIX D}

PANAS Mood Scale

\begin{tabular}{|ccccc|}
\hline 1 & 2 & 3 & 4 & 5 \\
$\begin{array}{c}\text { Very Slightly or Not } \\
\text { at All }\end{array}$ & A Little & Moderately & Quite a Bit & Extremely \\
\hline
\end{tabular}

\begin{tabular}{|ll|}
\hline 1. Interested & 11. Irritable \\
2. Distressed & 12. Alert \\
3. Excited & 13. Ashamed \\
4. Upset & 14. Inspired \\
5. Strong & 15. Nervous \\
6. Guilty & 16. Determined \\
7. Scared & 17. Attentive \\
8. Hostile & 18. Jittery \\
9. Enthusiastic & 19. Active \\
10. Proud & 20. Afraid \\
\hline
\end{tabular}

Reproduced from Watson, Clark, and Tellegen (1988). 